\title{
La Hacienda Pública Municipal ${ }^{1}$ Emilio Margáin Manautou²
}

SUMARIO:Introducción.II.Clasificación de los recursos municipales.III. Selección de las fuentes tributarias. IV. Características que debe reunir el tributo municipal. V. De los empréstitos. VI.EI Sistema Tributario Mexicano. VII.Ley de Coordinación Fiscal 1978. VIII. Evolución del Sistema Nacional de Coordinación Fiscal. IX. Exposición de Motivos de Reforma a la Ley de Coordinación Fiscal 2013 X. Exposición de Motivos de Reforma a la Ley de Coordinación Fiscal 2014. XI. Autonomía Financiera de los Municipios. XII. Conclusiones

\section{RESUMEN}

En el documento se hace un análisis de la actual situación de las haciendas públicas de los 2457 municipios en México a la luz de su inserción en el Sistema Nacional de Coordinación Fiscal(1980) y la Autonomía financiera concedida(1983) constitucionalmente (Artículo 115)para administrar libremente su hacienda y aprobar, entre otras, cada año calendario, sus presupuestos de egresos. El objetivo de la Ley de Coordinación Fiscal de fortalecer a los estados y municipios y hacerlos menos dependientes de la Federación no se ha alcanzado, el resultado es exactamente lo contrario, además de no establecer mecanismos para que se entreguen a tiempo y en cantidades suficientes las participaciones y transferencias para satisfacer las necesidades sociales a cargo de dichos entes, amén de otras calamidades.

Palabras clave: Coordinación Fiscal, Municipios, Hacienda Pública

\footnotetext{
1 Su inserción en el Sistema Nacional de Coordinación Fiscal y su Autonomía Financiera. Este documento forma parte de la Colección de Estudios Municipales publicada en Edición Especial de Biolex el mes de Julio de 2015.

2 Insigne Jurisconsulto,Catedrático Emérito de Derecho Fiscal y Administrativo de la Universidad Nacional Autónoma de México, ha recibido diversas distinciones de Universidades e Institutos de Educación Superior del país, así como la máxima presea que otorga la Universidad Autónoma de San Luis Potosí "ILDEFONSO DIAS DE LEON", Doctor Honoris Causa por el Centro de Investigaciones Jurídicas de Puebla, Creación de la Medalla al Mérito Académico Emilio Margáin Manautou, establecida el 16 de diciembre de 2011 por el Centro Nacional de Investigación Jurídica de Tlaxcala. Invitado Distinguido de Universidades Públicas (Universidad de Sonora, Invitado Distinguido de la Academia de Derecho Administrativo) y Privadas del País y del extranjero y autor de invaluables obras en las ciencias jurídico, económico, administrativas y sociales
} 


\section{La Hacienda Pública Municipal}

Volumen 12, Número 22 ene-jun 2020

Emilio Margáin Manaotou

\section{MUNICIPAL TREASURY}

Emilio Margáin Manautou

SUMMARY: Introduction. II. Classification of municipal resources. III. Selection of tax sources. IV. Characteristics that the municipal tax must meet. V. Of the loans. VI. The Mexican Tax System. VII. Fiscal Coordination Law 1978. VIII. Evolution of the National System of Fiscal Coordination. IX. Statement of reasons for the reform of the fiscal coordination law $2013 \mathrm{X}$. Statement of reasons for the reform of the fiscal coordination law 2014. XI. Financial Autonomy of the Municipalities. XII. Conclusions.

\section{ABSTRACT}

The document makes an analysis of the current situation of the public finances of the 2,457 municipalities in Mexico in light of their insertion in the National Fiscal Coordination System (1980) and the financial autonomy granted(1983) constitutionally (Article 115) to manage freely their finances and approve, among others, each calendar year, their expenditure budgets (1983). The objective of the Fiscal Coordination Law to strengthen the states and municipalities and make them less dependent on the Federation has not been achieved, and it does not have mechanisms so that participations and transfers are delivered on time and in sufficient quantities to satisfy the social needs in charge of said entities, in addition to other calamities.

Keywords: Fiscal Coordination, Municipalities, Municipal Treasury

\section{INTRODUCCIÓN}

Francisco de la Garza en su obra Hacienda Municipal ${ }^{3}$ justifica 0 fundamenta el derecho del Municipio de la percepción de ingresos, diciéndonos que satisface necesidades esenciales de su población, mediante la prestación de una serie de servicios públicos, cuya suspensión total o parcial, ocasionaría daños y perjuicios inmediatos, ingentes e irreparables, como lo serían el trastorno y molestias que acarrearían la falta de prestación de los servicios de barrido y limpieza de las calles, recolección de las basuras domiciliarias, de alumbrado

\footnotetext{
${ }^{3}$ Editorial, Jus. 1947.
} 
público, de abastecimiento de agua potable, de drenaje, de policía, etc., los que por su fundamental importancia es necesario que el Municipio tenga la seguridad permanente de poder prestar.

De ahí que es urgente que el Municipio goce de una sólida situación financiera que le permita mantener, permanentemente y en todo momento, la prestación de todos sus servicios públicos, que juegan un papel predominante en la vida municipal. ${ }^{4}$

\section{CLASIFICACIÓN DE LOS RECURSOS MUNICIPALES}

Dentro de la legislación y doctrina mexicana se han elaborado diversas clasificaciones de los recursos municipales, citándose como una de las más importantes las formuladas por.... Emilio Guzmán Lozano.... quien, en su ponencia presentada en la Tercera Convención Nacional Fiscal, ${ }^{5}$ clasifica a los recursos municipales en la forma siguiente: impuestos, derechos o tasas, participaciones productos y aprovechamientos.

En tratándose de los impuestos, considera que corresponde a los Municipios establecer el impuesto predial y los que recaigan sobre toda clase de recursos naturales que no sean de jurisdicción federal, espectáculos, actividades mercantiles e industriales, juegos permitidos, etcétera.

Los derechos o tasas deben establecerse exclusivamente en la prestación de servicios administrativos.

Respecto a las participaciones, Guzmán Lozano considera que el municipio debe participar en la recaudación que la Federación y los Estados obtienen dentro del mismo, en los casos siguientes:

\footnotetext{
${ }^{4}$ No obstante la reforma al artículo 115 Constitucional para dotar a los Municipios de mayores recursos, salvo verdaderas excepciones el grueso de sus percepciones están comprometidas en el pago del alumbrado el servicio público y en la introducción de agua potable, lo que ha orillado al legislador federal a autorizar e cobro por parte de los Municipios de los derechos por servicios de alumbrado público, aun cuando para su determinación se utilice como base el consumo de energía eléctrica - véase último párrafo del artículo 42 de la Ley del Impuesto al Valor Agregado.Algunos como el Municipio de Los Cabos, B.C. Sur, hasta crearon un impuesto sobre ingresos mercantiles disfrazado de contribución por mejoras, que el fisco federal en cumplimiento del convenio de coordinación fiscal, obligó a derogarlo.

5 "La Hacienda Municipal."
} 


\section{La Hacienda Pública Municipal}

Volumen 12, Número 22 ene-jun 2020

Emilio Margáin Manaotou

a) Recaudación de la Federación en el Municipio;

b) Recaudación del Estado en el Municipio, y

c) Cuando el funcionario municipal es recaudador o retenedor de la Federación o del Estado.

En los tres casos, dicho autor opina que al Municipio debe corresponderle como mínimo de participación el 10\% de la recaudación total.

\section{Clasificación que se Propone}

Atendiendo a las fuentes de recursos municipales y al orden en que deben ser estudiados por el funcionario para determinar los necesarios a satisfacer el presupuesto de egresos, se propone el siguiente procedimiento y clasificación:

a) En primer lugar, es necesario precisar a cuánto ascenderán los ingresos que proporcionarán los bienes propiedad del Municipio por su explotación, enajenación o rendimiento;

b) En seguida, determinar los servicios administrativos que los particulares solicitarán al Municipio, y cuyo costo es recomendable recuperar íntegramente mediante derechos 0 tasas;

c) En tercer término, precisar los servicios municipales que beneficiarán a toda la colectividad, pero en forma muy especial a determinadas personas, cuyo costo puede recuperarse por la aplicación de la contribución especial, de la que la contribución por mejoras es la figura principal;

d) Precisados los ingresos que rendirán los bienes del Municipio, los que se obtendrán por la prestación de servicios municipales requeridos por los particulares, así como los que se percibirán de aquellos habitantes que en forma especial se beneficiarán con ciertos servicios municipales generales divisibles, se deberán establecer los impuestos que aun sean necesarios para cubrir el presupuesto. Estos los podemos clasificar en: de participaciones y propios. 
Los impuestos de participaciones son las cantidades provenientes de la aplicación de un impuesto federal o estatal, en el que el Municipio tiene derecho sobre su rendimiento. Los impuestos propios son aquellos que gravan actividades cuyo rendimiento corresponde al Municipio en forma íntegra.

e) Dentro del rubro de los aprovechamientos debemos incluir todos los ingresos que percibe el Municipio no reputados como productos, derechos o tasas, contribuciones especiales 0 impuestos, en los que hay fuentes que proporcionan o pueden proporcionar ingresos de consideración, en ocasiones superiores al rendimiento de un gravamen, como, por ejemplo, los que se perciben por concepto de multas, y

f) Por último, tenemos a los empréstitos como fuente de recursos muy importantes para los Municipios, aún no explotada debidamente.

\section{III.SELECCIÓN DE LAS FUENTES TRIBUTARIAS}

No siempre es recomendable que por toda clase de servicios administrativos que se soliciten a las autoridades municipales se deba pagar necesariamente su precio. Tampoco en toda clase de servicios públicos generales divisibles debe pretenderse recuperar parte de sus costo, y es mala política la de gravar con impuestos hasta las menores actividades económicas que realicen los habitantes, pues es precisamente al fisco municipal a quien el contribuyente más exige por lo que paga; a quien más se le oponen los pagos y en quien desemboca todo desahogo contra lo que represente un Erario Público. 


\section{La Hacienda Pública Municipal}

Volumen 12, Número 22 ene-jun 2020

Emilio Margáin Manaotou

Ante la imposibilidad de enumerar los servicios administrativos que presta

el Municipio y por los cuales es recomendable la recuperación de su costo, mediante el pago del precio correspondiente, es preferible señalar los dos tipos de servicios en los que no es recomendable que el Municipio recupere su costo o exija precio alguno. Esos casos de excepción son los siguientes:

a) Cuando el pago del precio sea un estorbo de importancia para la obtención del bien común buscado. En efecto, el cobro de un precio aun cuando éste se político, muchas veces constituye un freno a la finalidad buscada por loa autoridad con la prestación del servicio, caso en el que es preferible que se abstengan de percibir cantidad alguna.

Por ejemplo, en el servicio escolar de educación primaria elemental que el Municipio debe prestar, un precio irrisorio o sea eminentemente político puede constituir, en muchas ocasiones, un serio obstáculo par que familias de escasos recursos económicos inscriban a sus hijos en las escuelas correspondientes.

b) Que la solicitud de prestación de un servicio sea consecuencia forzosa o caso forzoso del cumplimiento de una obligación impuesta por el mismo Municipio, excepto si esa obligación está relacionada con actividades lucrativas.

Hay obligación de votar en las elecciones municipales y para hacerlo debe obtenerse del Municipio la boleta de elector correspondiente, con lo que se debe solicitar un servicio a la autoridad para cumplir con la obligación que ella ha impuesto por lo que sería injusto que para satisfacerla se pretenda exigir un precio por el servicio que se presta.

En cambio, no es criticable que se pague el precio del servicio, cuando no obstante solicitarse porque lo exija la ley, se experimente un beneficio económico. 
Hay obligación de que todo aparato de pesas o de medir que se utiliza en el comercio, se someta periódicamente a revisión; por lo tanto, si todo comerciante, como consecuencia del servicio que se ha obligado a solicitar, experimente un beneficio económico, justo es que pague el costo del mismo.

La contribución especial es una figura jurídica tributaria que podemos considerar todavía como de reciente creación y que no se encuentra debidamente explotada por los Municipios, ya que a través de ella puede recuperarse si no la totalidad cuando menos buena parte del costo de un servicio municipal de carácter divisible, de servicios municipales que benefician en forma general a toda la colectividad y de manera muy especial a determinados habitantes.

Dos son los tipos de contribuyentes que la doctrina encuentra en esta figura:

a) Aquéllos que encontrándose en determinada situación experimentan una particular ventaja económica, como consecuencia de una actividad administrativa de interés general. Estos sujetos son los propietarios de los inmuebles que se encuentran dentro del área geográfica en la que se estima que se derramarán los beneficios económicos producidos por una obra ejecutada por el Estado. Estas obras son: Apertura o ampliación de calle o avenida; creación o ampliación de parques o jardines, y urbanización de la vía pública; etcétera.

b) Aquéllos que como consecuencia de las cosas que poseen o del ejercicio de una actividad industrial, comercial, o de otra actividad provoquen un gasto o un aumento en el gasto público. Quien pretenda, por ejemplo, crear un fraccionamiento, sea popular o residencial, debe considerar que va a provocar un nuevo gasto o un aumento en el gasto municipal.

En efecto, la creación de un nuevo centro de población origina para el Municipio problemas tales como un mayor consumo de agua potable y, por lo tanto, necesidad de realizar obras de captación e introducción de dicho líquido; ampliación de los servicios de seguridad, de limpieza, de escuelas, de áreas verdes, etc., por lo que es justo que el fraccionador contribuya de manera muy especial a satisfacer ese aumento del gasto público, mediante la entrega de las superficies requeridas para parques y jardines, para construcción de una escuela 


\section{La Hacienda Pública Municipal}

Volumen 12, Número 22 ene-jun 2020

Emilio Margáin Manaotou

y de un mercado, y la aportación económica para la introducción de agua potable, etcétera.

La única excepción que puede señalare para la aplicación de la contribución especial la encontramos en aquellas obras municipales que con su sola explotación permitirán la recuperación de su costo, en las que no es recomendable su exigencia. Por ejemplo, la construcción de mercados.

Por el impuesto, que es el que proporciona los mayores ingresos, los Municipios perciben recaudación, tanto por las participaciones que les corresponden en el rendimiento de impuestos federales y estatales, como del rendimiento de los establecidos como propios. Esta fuente impositiva debe aplicarse esencialmente a la propiedad de inmuebles, a las actividades mercantiles e industriales, a las actividades agrícolas y ganaderas, etcétera.

\section{CARACTERÍSTICAS QUE DEBE REUNIR EL TRIBUTO MUNICIPAL}

Atendiendo al tipo de contribuyentes que tiene el Municipio, a su número y al contacto casi diario que con ellos se mantiene, el tributo municipal debe llenar las siguientes características:

a) Sencillo en su redacción para su mejor compresión, por lo que es recomendable que en los ordenamientos que se expidan se use un lenguaje liso y llano, exento, hasta donde sea posible, de términos eminentemente técnicos o jurídicos.

b) Ágil en su determinación que fácil y rápidamente pueda precisarse la cantidad a pagar por el contribuyente;

c) Económico en se recaudación, lo que permitirá destinar el máximo a servicios públicos, y

d) Cómodo en su cobro, esto es, debida selección de la época de pago; evitar molestias y la realización de engorrosos trámites administrativos o de largas esperas para el pago.

El Municipio es el sujeto activo que tiene como contribuyentes a toda una gama de personas, desde el comerciante, el industrial, el ganadero, el profesional, el 
propietario de inmuebles, etc., hasta el simple estudiante y ama de casa. De los tres sujetos activos -Federación, Estados y Municipios- estos últimos son los que tienen contacto más cercano con los contribuyentes y, por lo tanto, los más expuestos a críticas y a sufrir las contrariedades y el mal estado de ánimo de los mismos, no sólo cuando existen malas administraciones municipales, sino cuando las hay por parte de la Federación o el Estado.

\section{Cuotas Tasas o Tarifas a implantarse}

De los impuestos. En la actualidad, salvo verdaderas excepciones, los Municipios en Latinoamérica requieren en alto grado de establecer cuotas, tasas o tarifas que contribuyan a hacer ágil la aplicación de los impuestos, pues son los Municipios los que con mayor desesperación necesitan que la administración de los gravámenes sea lo más económica posible. Por ello atendiendo a la actividad o clase de contribuyentes, debe implantarse la cuota, tasa o tarifa que proporcione los mayores rendimientos posibles. Así tenemos:

a) La ganadería. Lo ideal es establecer una tasa o tarifa que se aplique en atención al valor del ganado objeto de la operación, ero la experiencia ha demostrado que cuando ha sido así, hay continuo contubernio entre los ganaderos y los compradores del ganado para facturar a precios inferiores a los reales. Además, es muy difícil controlar las operaciones que se realizan entre ganaderos y los compradores del ganado para facturar a precios inferiores a los reales. Además, es muy difícil controlar las operaciones que se realizan entre ganaderos, por lo que es de recomendarse que, mediante estudios económicos, se asigne una cuota fija por cabeza de ganado que se enajene.

Como las transacciones con ganado son de difícil verificación y sólo tienen dos puntos u operaciones de control, que son el de exportación y la entrada a los rastros para su matanza, es por lo que en el primer caso, atendiendo a la clase 0 tipo de ganado, debe asignarse una cuota fija de impuesto a pagar, independientemente del importe de la operación y una cuota por kilo en el 


\section{La Hacienda Pública Municipal}

Volumen 12, Número 22 ene-jun 2020

Emilio Margáin Manaotou

segundo caso. Es injusto que en la matanza de ganado se exija una cuota fija, independientemente del peso del animal.

b) La agricultura. Como el grueso de los agricultores de escasos conocimientos, de baja capacidad económica y, además, permanece alejado de problemas administrativos, es de recomendarse que, mediante estudios económicos, se les determine la cantidad a pagar atendiendo a la superficie y a la clase de productos que cultiva. En tratándose de citricultores, por ejemplo se puede simplificar aún más el impuesto a pagar, mediante la adopción de una cuota específica por árbol de producción.

c) Del comercio y la industria. De acuerdo con la Ley de Coordinación Fiscal, los municipios no pueden gravar ninguna actividad empresarial, recibiendo a cambio cantidades mensuales provenientes de lo que les corresponde en la participación estatal en los términos de dicha Ley, no siempre

suficiente como para satisfacer con los demás recursos las necesidades sociales a cargo de ellos, obligando, como ya hemos visto, a un municipio a crear un impuesto sobre ingresos mercantiles disfrazado de contribución por mejoras y a otro un impuesto de radicación, ante la angustia de falta de recursos.

La coordinación fiscal impuesta por la Federación ha lesionado la economía de los municipios importantes del país, por cuanto que antes de la coordinación percibían más. Sin embargo, la mayoría de los municipios sí han resultado favorecidos, pero ante el déficit en la recaudación tributaria las necesidades sociales a su cargo los han desbordado, incurriendo en contante adeudo con la Comisión Federal de Electricidad y la Comisión Nacional del Agua.

En los derechos o tasas, la doctrina recomienda que el sujeto activo, en tratándose de la prestación de servicios administrativos, recupere sólo el costo de los mismos, pues si el precio a pagar está muy por encima de él, entonces estaremos en presencia de un impuesto y no de un derecho o tasa.

Sin embargo, la regla anterior debe tener sus casos de excepción. En ocasiones, el Municipio puede determinar el costo de un servicio, pero no la medida en que será solicitado o utilizado por el habitante. En unos casos no sería justo que pagase el mismo precio quien utilice el servicio con moderación, que 
aquél que lo utiliza en abundancia; pero en otros ante la imposibilidad de distinguir, es correcto que los usuarios paguen cantidades iguales. Por ejemplo, el caso del servicio de transportación municipal: paga lo mismo quien utiliza el servicio para viajar seis cuadras, que quien viaja diez, doce o más cuadras.

Pero en tratándose, por ejemplo, del servicio de agua potable, no es correcto que se aplique solamente una cuota fija a pagar por $\mathrm{m}_{3}$ de agua consumida, sino que lo adecuado es la implantación de una tarifa progresiva. A mayor consumo, aplicación de mayores tasas. Contribuirá a hacer más justo lo anterior, el que se distinga, además entre el consumo de las zonas residenciales de primer orden, y el de aquéllas que no lo son.

En la contribución especial, la cantidad a pagar se debe obtener mediante la derrama del costo del servicio público general divisible entre los propietarios de los predios situados dentro del área geográfica en que el legislador estima que se alcanzarán los beneficios de la obra, atendiendo a la superficie que se posee y su cercanía a la obra ejecutada.

Esta figura debe aplicarse con mucho cuidado, pues puede crear graves malestares ${ }^{6}$ y contribuir a que propietarios de baja capacidad económica se vean desposeídos de su propiedad por la falta de pago, o bien obligados a enajenar, sin aprovecharse de los beneficios económicos de la obra.

\section{DE LOS EMPRÉSTITOS}

Esta fuente de ingresos no ha sido correctamente aprovechada por los Municipios, pues a través de ella podrían satisfacerse necesidades que permitiesen recuperar su costo y, por ende, pagar el empréstito.

El Municipio, para la realización de obras de servicio público general divisible, podría financiar su costo a través de empréstitos, previendo el pago de los mismo con la recuperación de su costo mediante la aplicación de la figura jurídica tributaria de la contribución especial. Asimismo, podría recurrirse a este tipo de financiamiento para obras o servicios que con su sola explotación pueden

\footnotetext{
${ }^{6}$ La aplicación de este tributo hace pensar de inmediato al contribuyente en qué es lo que se hace con lo que se recauda por concepto de impuestos.
} 


\section{La Hacienda Pública Municipal}

Volumen 12, Número 22 ene-jun 2020

Emilio Margáin Manaotou

pagarse, como por ejemplo, la construcción de mercados, aeropuertos municipales, servicios de transportes urbanos, etcétera.

Lamentablemente, salvo verdaderas excepciones, las experiencias que se han tenido con estas fuentes de ingreso no han sido satisfactorias. Ello es imputable a erróneos estudios económicos o a fugas, que impiden que la obra 0 el servicio financiado pueda satisfacer los adeudos en las condiciones y plazos originalmente señalados, por lo que las restante fuentes de ingresos soportan el pago de los adeudos, con grave perjuicio de otros servicios municipales, pues en esos casos los rendimientos del servicio municipal financiado quedan afectados durante un buen número de años, en exceso de lo planeado. Es por esto que las autoridades estatales deben intervenir en la contratación de empréstitos por parte de los Municipios, con el objeto de evitar endeudamientos en exceso de capacidades de pago, sobre todo, para obras que no pueden satisfacer su costo.

Sin embargo, los empréstitos, como fuentes de financiamiento de servicios municipales, son de suma importancia y bien planeada su contratación, los beneficios económicos que experimentarían los habitantes, serían extraordinarios.

En la actualidad peligrosa se ha vuelto esta figura como medio de financiamiento de obras municipales por la desviación de los recursos, salvo para la construcción de mercados e introducción de agua potable o de drenaje para la intervención del banco de obras y Servicios Públicos, que es oficial.

\section{EL SISTEMA TRIBUTARIO MEXICANO ${ }^{7}$}

La Constitución Mexicana, bajo el sistema federal que adopta, reconoce, la existencia de tres entes con facultades impositivas: la federación los estados y los municipios. El hecho de que puedan existir tres impuestos idénticos gravando el mismo objeto, pertenecientes a tres entes, o bien tres sistemas impositivos,

\footnotetext{
${ }^{7}$ Margáin Manautou Emilio, “Nociones de Política Fiscal”, México, Ed. Porrúa, 1998, pp.220 y ss.
} 
indudablemente que ello afecta a la marcha económica del país. Si a lo anterior agregamos que el fisco local puede actuar en forma independiente del fisco federal, complicando ello las obligaciones a cargo de los contribuyentes; que el Distrito Federal, sede del gobierno federal, también posee impuestos locales; que hay estados productores, que son los ricos que exportan parte de su producción hacia los estado consumidores, que son los pobres, absorbiendo buena porción de la economía de estas entidades sin pagar impuestos en las mismas, tenemos que concluir que todo esto viene a influir en la vida económica de los habitantes del país.

El problema económico que deriva de la triple imposición nacional, ha sido atacado por la federación de manera especialmente durante cerca de los últimos cincuenta años, siempre sobre la base de no debilitar al federalismo existente.

Primero, a fines del siglo XIX, se logró que se reconociese por las entidades federativas que sólo la federación podía gravar la entrada y salida de mercancías del territorio nacional con impuestos aduaneros; la circulación de ellos por territorio nacional; el establecimiento de impuestos diferenciales etc. Lo cuál se incorporó en el artículo 117 Constitucional

Por reforma introducida en la Constitución en el artículo 73 fracción XXIX, en 1942, se señalaron cuáles son las fuentes económicas que sólo la federación puede gravar y que ha dado origen a lo que se conoce, como "fuentes exclusivas de la federación"; sobre las restantes no previstas en esta disposición, tanto la federación, los estados y los municipios concurren a gravarlas y se conocen como "fuentes concurrentes".

No obstante que los estados delegaron a la federación las facultades para gravar en forma exclusiva determinadas fuentes económicas, la federación se arroga facultades que no le corresponden para gravar otras fuentes económicas no delegadas por los estados, con lo que según unos se viola el pacto federal; pero según otros, no hay tal violación en virtud de que la federación puede establecer las contribuciones que basten a cubrir el presupuesto, en los términos de la fracción VII del mismo precepto constitucional. 


\section{La Hacienda Pública Municipal}

Volumen 12, Número 22 ene-jun 2020

Emilio Margáin Manaotou

Desde la década de los treinta la federación empezó a invitar a los estados para que se coordinasen en los impuestos federales similares a los que éstos mantienen en vigor, a condición de que deroguen todos los tributos que en una u otra forma gravan lo mismo. Así se logró que los estados se coordinasen al impuesto federal a la producción y consumo de cerveza, de cerillos y fósforos, de energía eléctrica, etc., y una vez que hubo mayoría de entidades coordinadas, la federación promovió la reforma constitucional correspondiente, contando con el voto de las entidades coordinadas y en tal forma se fue apropiando de importantes fuentes económicas.

Por ello los estados, sobre todo los más importantes, al surgir nuevos impuestos federales con el atractivo de la coordinación y participación en el rendimiento del impuesto, siempre que derogasen su impuesto local gravando la misma fuente económica, como el de aguas envasadas,cemento,ingresos mercantiles,etc., se abstuvieron de coordinarse.

En 1969 ,al crear la tasa especial del $10 \%$ en el impuesto sobre ingresos mercantiles, se consignó en la ley de la materia que tendrían derecho a participar en el $40 \%$ del rendimiento de esta tasa las entidades que se coordinasen a ella, aún cuando no lo estuviesen con la tasa general; en el entendido de que las entidades que no lo hicieren perderían su participación, que engrosaría a las arcas de la federación y con ello obligando a los contribuyentes de esas entidades a pagar tres impuestos en lugar de uno: la tasa especial del 10\%,la estatal del 1\% más $15 \%$ adicional y la municipal del .20\%.El atractivo para los estados renuentes a la coordinación fue extraordinario: derogar el $1.2 \%$ y adicional, a cambio de un $4 \%$.

En diciembre de 1972 se deroga la tasa local en el impuesto federal sobre ingresos mercantiles del $1.2 \%$ que se otorgaba a los estados coordinados, creándose una sola tasa general del $4 \%$ con derecho a participar en ella en un $45 \%$ de no existir coordinación, los contribuyentes de esas entidades reacias cubrirían: la tasa general del $4 \%$ y diversas especiales que van del 5,10,15 y $30 \%$;la tasa local del $1 \%$ y adicional y la municipal del .20\%. 
Como es natural los contribuyentes de las entidades no coordinadas fueron los que mas presión hicieron para que sus gobernadores procedieran a aceptar la coordinación. El mismo procedimiento se siguió con el resto de los impuestos federales gravando fuentes concurrentes, desapareciendo los impuestos estatales y municipales.

Es indudable que desde el punto de vista económico lo ideal es que exista, como lo ha dicho la Suprema Corte de Justicia de Argentina, para un solo territorio un solo impuesto. Sin embargo; hay que aducir que esto constituye un fuerte ataque al pacto federal.

El gobierno Federal americano promovió reformas a su sistema impositivo con el fin de otorgar participación a estados y municipios en el rendimiento del impuesto sobre la renta, siempre que no mantuviesen en vigor leyes o sistemas que contuviesen, por ejemplo, indicios de discriminación, pero hubo algunos municipios que renunciaron a esa participación, no porque desearan tener en vigor leyes consideradas como discriminatorias, sino simplemente porque sabían que si aceptaban esa participación ya no iban en el futuro a poder dejar de prescindir de ella, con lo cuál consideraban que ponían en peligro su independencia o libertad económica y de actuación frente a la federación.

En México por razones políticas, ninguna entidad federativa se ha distinguido por su celo soberano.

En tanto se desarrollaba el sistema de coordinación en materia impositiva, se sostuvo la tesis de que siendo la nación la propietaria originaria de los bienes y recursos naturales a que aluden los párrafos cuarto y quinto del artículo 27 Constitucional y la federación su representante, sólo ésta podía gravar esos bienes y recursos naturales a que aluden los párrafos cuarto y quinto del artículo 27 Constitucional y la federación su representante, sólo ésta podría gravar esos bienes y recursos naturales. Los estados no objetaron esa tesis y así se empezó a observar entidades ricas en dichos bienes y recursos, pero pobres en lo económico por carecer de otras fuentes económicas.

\section{LEY DE COORDINACIÓN FISCAL LCF 1978}




\section{La Hacienda Pública Municipal}

Volumen 12, Número 22 ene-jun 2020

Emilio Margáin Manaotou

En enero de 1978 entró en vigor una parte de la actual Ley de Coordinación Fiscal LCF, conforme a la cual la federación otorga a los estados y municipios participación en los impuestos federales, salvo los aduaneros y alguno otro, bajo un sistema que no inspira confianza a los señores gobernadores ya que será el gobierno federal la que haga la distribución que corresponda. Para apoyar este nuevo ordenamiento, que examinado con detenimiento sólo permitirá a los estados y municipios a establecer no más de cuatro o cinco impuestos: predial, sobre nóminas, sobre traslación de dominio, a los profesionistas independientes y sobre automóviles usados que enajenan particulares a particulares, lo que se expresa en la Exposición de Motivos :

El Ejecutivo de mi cargo, con fundamento en el artículo 71, fracción I, de la Constitución Política de los Estados Unidos Mexicanos, por el digno conducto de ustedes, somete a la consideración del H. Congreso de la Unión, la presente iniciativa de Ley de Coordinación Fiscal, la cual se fundamenta en las siguientes consideraciones:

La revisión que se ha efectuado de los principales impuestos de la Federación a que se refieren Iniciativas presentadas por separado a Vuestra Soberanía, conducen necesariamente a considerar el problema de coordinación fiscal entre la Federación, el Distrito Federal, los Estados y los Municipios del país.

La Constitución Política de los Estados Unidos Mexicanos no ha separado las fuentes de tributación que deban corresponder a cada uno de los niveles de gobierno, con la sola excepción de la fracción XXIX del artículo 73 que se adicionó a la Carta Fundamental y que reservó algunas fuentes que se decidió quedaran gravadas exclusivamente por la Federación; pero en dicha fracción no quedan comprendidos los principales impuestos federales $y$, por otra parte, nuestra Carta Fundamental no establece impuestos reservados en forma exclusiva a los Estados, ni a los municipios. 
El sistema constitucional permite a la Federación, en los términos de la fracción VII del artículo 73, establecer las contribuciones necesarias para cubrir el presupuesto de gastos de la Federación, sin que esto quede limitado a los gravámenes enumerados en la fracción XXIX del propio precepto. Los Estados, con apoyo en el artículo 124 tienen facultad para establecer las contribuciones

necesarias para cubrir los presupuestos estatales y el artículo 115 da facultad a las Legislaturas de los Estados para decretar los impuestos destinados a cubrir los gastos públicos Municipales.

\section{Doble o múltiple tributación interior}

La circunstancia de que los textos constitucionales no delimitan campos impositivos federales; estatales y municipales, determina que tanto el Congreso de la Unión, como las Legislaturas de los Estados, puedan establecer contribuciones sobre las mismas fuentes. Cuando ello ocurre se da lugar a la doble o múltiple tributación interior, consecuencia de la concurrencia o coincidencia en el ejercicio de facultades impositivas de Federación y Estados.

Debe reconocerse que la concurrencia impositiva está permitida en la Constitución e implicada en la fracción IV del artículo 31 de su texto; pero de ello no puede derivarse la conclusión de que el constituyente hubiera querido que cada fuente fuera gravada con impuestos federales, estatales y municipales. La conclusión correcta no puede ser otra que la que el constituyente no juzgó necesario o conveniente separar las fuentes tributarias exclusivas de Federación, Estados y Municipios.

Lo antes señalado no impide, sino por el contrario supone, que tanto el Congreso de la Unión como las Legislaturas de los Estados actúen con la prudencia necesaria para no superponer gravámenes sobre la población contribuyente. 


\section{La Hacienda Pública Municipal}

Volumen 12, Número 22 ene-jun 2020

Emilio Margáin Manaotou

Con esta prudencia ha ocurrido que ciertos gravámenes, como los relativos a la propiedad raíz, han venido quedando reservados, de hecho, a los Estados y otros como el de la renta que grava a las empresas, han sido establecidos únicamente por la Federación.

La prudencia de los legisladores federales y estatales los ha llevado incluso a buscar acuerdos para que sólo una u otros graven determinada materia, compartiendo el producto de su recaudación y estableciendo las bases de colaboración administrativa en determinados impuestos de interés común para Federación y Estados. Surgió así el procedimiento de participaciones en impuestos, expresamente reconocido en la Constitución Política, que ha constituido uno de los principales alivios a los problemas derivados de la concurrencia impositiva.

El acuerdo entre Federación y Estados no se ha limitado a las fuentes de impuestos señaladas en la Constitución, sino que se ha extendido a otras contribuciones federales en las cuales los Estados y los Municipios reciben participación a cambio de abstenerse de gravar la misma fuente. Esta abstención no constituye una restricción o limitación que vulnere la soberanía de los Estados; por el contrario, dicha soberanía se manifiesta y se ejerce cuando una entidad federativa decide dejar en suspenso la aplicación de sus propias leyes o no dictarlas, a cambio de recibir participación en el impuesto establecido por la Federación.

El ejemplo más característico de armonía o coordinación entre Federación y Estados en materia fiscal, lo constituyó el impuesto federal sobre ingresos mercantiles, por medio del cual se establece un gravamen sobre el comercio y la industria que se comparte entre Federación, Estados y Municipios, en relación con el cual sólo legisla la Federación y los Estados han realizado una amplia colaboración en tareas administrativas. 
La uniformidad del impuesto al comercio y a la industria ha facilitado su desarrollo, al evitar que surjan barreras o restricciones entre los Estados, las más severas de las cuales suelen ser las de carácter fiscal. Ello ha hecho también innecesario que el Congreso de la Unión haga uso de las facultades que le concede la fracción IX del artículo 73 de la Constitución Política.

Paralelamente y en muy diversas materias, los Estados se han venido acogiendo a participaciones otorgadas por las leyes federales, absteniéndose de gravar las mismas materias en los términos previstos en aquellas leyes; pero como el sistema de participaciones se desarrolló históricamente en diversas etapas y conforme a diferentes criterios, resulta que el conjunto del sistema tributario federal, falta racionalidad en cuanto a la determinación de los impuestos en que sí se otorgan participaciones y aquellos otros cuya recaudación se destina exclusivamente a la Federación. Falta también uniformidad y armonía en cuanto al monto y procedimiento para distribuir las participaciones entre las diversas entidades federativas.

Finalmente, la decisión de la Federación de transformar y modernizar el impuesto federal sobre ingresos mercantiles $y$ sustituirlo por el impuesto al valor agregado, como en Iniciativa por separado se ha propuesto a Vuestra Soberanía, obliga a revisar todos los procedimientos de participación y reunirlos en un solo sistema al cual la presente Iniciativa llama Sistema Nacional de Coordinación Fiscal.

Dentro de dicho sistema, ya no se otorgan participaciones sólo respecto de ciertos impuestos federales, sino que la parte que corresponde a Estados y Municipios se determina en función del total de impuestos federales, incluyendo aquellos que tradicionalmente se consideraron de recaudación exclusiva de la 


\section{La Hacienda Pública Municipal}

Volumen 12, Número 22 ene-jun 2020

Emilio Margáin Manaotou

Federación, como son los impuestos a las importaciones y a las exportaciones. El mayor dinamismo del sistema fiscal federal en su conjunto, comparado con el de los impuestos federales participables.

Esta relación es de $12.07 \%$ en el año de 1978. Es decir, que el conjunto de participaciones que recibirán los Estados en este ejercicio en ingresos mercantiles, impuestos especiales y otras contribuciones de la Federación, es el $12.07 \%$ de la recaudación federal total.

Esta iniciativa no propone el aumento de este tanto por ciento, no obstante que se reconoce que en general, los Estados sufren serias carencias financieras; pues la relación ingreso gasto de la Federación no hace posible efectuar en el ejercicio de 1979 una mayor transferencia; pero al establecer el por ciento de la misma en la ley, evitará que se siga deteriorando este importante renglón de ingresos de los Estados; al mismo tiempo que los hace compartir el aumento que en el conjunto del sistema fiscal espera la Federación. Por otra parte, el sistema facilita a futuro mejorar la participación global de los Estados en la medida en que lo permitan las condiciones financieras de la Federación. Esta mayor transferencia a futuro, habrá de justificarse mediante la asunción por parte de los Estados, de obras públicas y servicios de carácter local, que serán realizadas o prestados con más eficiencia por las entidades federativas y que viene realizando la Federación ante la falta de recursos económicos de aquellas. Estamos convencidos de que una mejor distribución del ingreso fiscal entre Federación y Estados y una reasignación de atribuciones entre una y otros, constituye un instrumento idóneo para el fortalecimiento de nuestro federalismo.

Llegar a dotar de más recursos a los Estados, dará a éstos la base económica indispensable para que hagan lo mismo con sus Municipios. El fortalecimiento de la institución municipal constituye la 
base y garantía de nuestro desarrollo democrático. Por ello, desde ahora, se mantiene en el contenido de la presente Iniciativa la exigencia de que los Estados que se coordinen, entreguen a sus Municipios cuando menos el $20 \%$ de las participaciones que correspondan a aquellos. Exigencia que no es nueva y que se recoge de los textos de la Ley del Impuesto sobre Ingresos Mercantiles próxima a ser derogada y de las disposiciones contenidas en la mayor parte de las leyes que establecen impuestos federales participables. No se establecen otras medidas en beneficio de la hacienda municipal, en razón de que conforme al artículo 115 de la Constitución Política, esto es facultad y responsabilidad de las Legislaturas de los Estados.

Los Estados de la República, en ejercicio de su soberanía, podrán solicitar adherirse al Sistema Nacional de Coordinación Fiscal, en cuyo caso, la Secretaría de Hacienda celebrará con ellos, un convenio de coordinación fiscal que les dará derecho a participar en un Fondo General de Participaciones formado con el $13.0 \%$ de la recaudación federal total que se incrementará con el porciento que represente en dicho ingreso de la Federación la recaudación de gravámenes locales o municipales que las entidades convengan en derogar o dejar en suspenso. Dicho fondo será distribuido entre los Estados conforme a las bases establecidas en la Ley que se propone y que se desarrollen en los citados convenios. A cambio de esta participación, los Estados no impondrán gravámenes o los mantendrán en suspenso, sobre las materias establecidas en las leyes federales relativas a impuestos participables, modalidad que no se hace extensiva en relación a otros impuestos en los cuales no ha existido participación a los Estados.

El acto de adhesión por Convenio al Sistema Nacional de Coordinación Fiscal tiene importancia relevante para los Estados, ya que deja en suspenso, mientras dura el convenio, algunos de los 


\section{La Hacienda Pública Municipal}

Volumen 12, Número 22 ene-jun 2020

Emilio Margáin Manaotou

impuestos establecidos por su Legislatura o impone abstención al propio Estado, por todo lo cual el convenio se rodea de formalidades especiales, debiendo ser aprobado, según lo dispongan las normas locales, por la Legislatura de cada entidad.

El H. Congreso de la Unión es también el poder legislativo local del Distrito Federal. Con base en ello, esta Iniciativa propone que el propio Distrito, sin que medie convenio, quede adherido al Sistema de Coordinación Nacional Fiscal al entrar en vigor la Ley a que se refiere la presente Iniciativa.

Los Estados de la República, si así lo prefieren, pueden no adherirse al Sistema Nacional de Coordinación Fiscal, en cuyo caso, podrán establecer libremente los impuestos que estimen convenientes, salvo los señalados en la fracción XXIX del artículo 73 constitucional, en relación con los cuales seguirán recibiendo las participaciones señaladas en las leyes federales.

Las participaciones tradicionales en impuestos federales y aun el funcionamiento del Fondo General de Participaciones que se proponen, tienen como consecuencia que las entidades que generan mayores volúmenes de impuestos federales, son las que también reciben las mayores proporciones por concepto de participaciones. Ello es natural y debido; pero produce el inconveniente de que los Estados de menor desarrollo económico relativo, no obtengan de la distribución de participaciones, recursos que los auxilien para acelerar su desarrollo social y económico. A través de un largo diálogo entre los Estados y la Federación, se ha encontrado un camino para aliviar situaciones como la descrita a través de la creación en forma permanente, de un Fondo Financiero Complementario de Participaciones que se distribuya entre los Estados en proporción inversa a las participaciones que reciban del Fondo General y al gasto corriente en materia educativa que realice la Federación en cada una de las entidades. 
En esta forma y tomando en cuenta, además, la población de cada Estado, pueden hacerse llegar recursos adicionales a las entidades menos favorecidas con el funcionamiento normal de participaciones. Ello ya fue intentado, pero por una sola vez en el ejercicio que termina. El $0.37 \%$ de la recaudación total federal, que se propone en esta iniciativa para llevarla al citado Fondo Financiero Complementario, dará a los Estados en el ejercicio de 1979 la cantidad estimada de unos mil millones de pesos. Las entidades que decidan adherirse al Sistema Nacional de Participaciones compartirán los recursos del Fondo General Complementario.

Como el Sistema Nacional de Coordinación Fiscal, que se basará en las leyes y se desarrollará en convenios que celebren los Estados y la Federación, implica que los Estados no graven las fuentes en relación con las cuales reciben participaciones, es conveniente, si se busca preservar dicho Sistema y facilitar su desenvolvimiento futuro, que se establezcan procedimientos para resolver los problemas que pudieren presentarse y mantener las relaciones entre la Federación $y$ las Entidades en un plano constante de entendimiento.

El Estado que se considere afectado por decisiones de la Federación, podrá acudir en juicios de nulidad ante la Suprema Corte de Justicia de la Nación, con base en los dispuesto por el artículo 105 de nuestra Constitución Política. Las controversias entre la Federación y una entidad federativa han caído en desuso en nuestro derecho público. Sin embargo, las mismas pueden involucrar importantes aspectos de interpretación jurídica cuya solución adecuada corresponderá a nuestro más Alto Tribunal.

Para ello se establece en esta Ley el procedimiento correspondiente, en la convicción de que con ello se da vida a nuestras instituciones constitucionales.

La colaboración administrativa de los Estados con la Federación para realizar tareas de recaudación, fiscalización y en general de 


\section{La Hacienda Pública Municipal}

Volumen 12, Número 22 ene-jun 2020 Emilio Margáin Manaotou

administración de impuestos federales, ha sido una fecunda experiencia que ha demostrado un amplio grado de desarrollo de la capacidad administrativa de las entidades federativas. Esta colaboración ha hecho posible, en los últimos años, obtener un importante aumento en la recaudación del impuesto federal sobre ingresos mercantiles y de otros impuestos de la Federación. Por esta razón la Iniciativa propone institucionalizar los convenios entre la Federación y los Estados para realizar de común acuerdo tareas de administración fiscal. En el caso del Departamento del Distrito Federal y dado su carácter de órgano de la administración pública federal, la colaboración administrativa se realizará con base en acuerdos que dicte el Ejecutivo de la Unión.

La coordinación de los sistemas fiscales de la Federación, Estados y Municipios no se inicia ni termina con la Ley que se propone en esta Iniciativa. Con ella sólo se está cubriendo una etapa más de un proceso iniciado años atrás y que habrá de seguir un largo camino en el futuro. La coordinación fiscal es un proceso dinámico que requiere órganos propios que lo hagan posible, lo vigilen y lo promuevan. Para todo ello se propone que la Ley cree y organice como órgano de coordinación, a la Reunión Nacional de Funcionarios Fiscales, a la Comisión Permanente de Funcionarios Fiscales y al Instituto para el Desarrollo Técnico de las Haciendas Públicas. Con ello no se están inventando nuevos instrumentos.

Sólo se está dando vida institucional a mecanismos que el desarrollo de las relaciones entre los Estados y la Federación han ido haciendo convenientes, ellos han sido los creadores y promotores de los adelantos logrados en los últimos años en materia de coordinación fiscal."

\section{EVOLUCIÓN DEL SISTEMA NACIONAL DE COORDINACIÓN FISCAL}


Han transcurrido mas de tres décadas desde que se implementó el Sistema Nacional de Coordinación Fiscal y los y estados y los municipios en nuestro país por razones de extensión, riqueza o ubicación geopolítica, lejos de experimentar una evolución sostenida han crecido con ritmo asimétrico ensanchándose cada vez mas la brecha entre los considerados desarrollados y los menos desarrollados, quedando distante el alcanzar

"una mejor distribución del ingreso fiscal entre Federación y Estados...para el fortalecimiento de nuestro federalismo...y la base económica indispensable para ....el fortalecimiento de la institución municipal". En este punto nos es dable recordar que al inicio de la aplicación de la Ley de Coordinación Fiscal, (Diciembre de 1978 y 1980), que "contiene la reglamentación del Ramo 28, (Participaciones a Estados y Municipios)... este Ramo se componía principalmente del Fondo General de Participaciones que significó el $13 \%$ de los ingresos federales. Los recursos fueron incrementándose paulatinamente al involucrar otros conceptos de la armonización tributaria, hasta significar en 1995 el $18.51 \%$.

A partir del año de 1996, estos recursos se constituyen con el $20 \%$ de la recaudación federal participable .Ramo 28 : "Participaciones a Entidades Federativas y Municipios" Las participaciones provienen de la distribución intergubernamental de los recursos entre la federación, las entidades federativas (Estados) y los municipios. Entre ellos, se distribuyen la recaudación total de acuerdo al Sistema Nacional de Coordinación Fiscal. Las participaciones federales a estados y municipios están constituidas por dos fondos principales: el Fondo General de Participaciones FGP y el Fondo de Fomento Municipal FFM. Del primer fondo, se le destinan obligatoriamente a los municipios al menos el 20 por ciento de los recursos transferidos a los estados también por dicho fondo. Esta norma data desde 1980 y solo se modificó al desaparecer el Fondo Financiero 


\section{La Hacienda Pública Municipal}

Volumen 12, Número 22 ene-jun 2020

Emilio Margáin Manaotou

Complementario FFC, el cual se distribuía en razón inversa a la distribución del Fondo General de Participaciones FGP es decir--como ya se mencionó líneas arriba--- la proporción menor del FFC se entregaba a aquel Estado a quien le hubiese correspondido la mayor parte del FGP.

El segundo fondo (Fondo de Fomento Municipal - FOMUN ), se conforma con el 16.8 por ciento del 1 por ciento de la recaudación federal participable, y se distribuye a los municipios a través de los estados, garantizando que las cantidades no sean menores a lo recaudado localmente por impuesto predial y por derechos. Con el paso de los años, el Ramo 28 tiene ahora 13 fondos, y 5 formulas específicas con variables adicionales a ellas que urge sean revisadas. De esta manera, las participaciones federales significan la única fuente de recursos descentralizados que se maneja libremente por las legislaturas locales y se convierte en recursos ordinarios y propios para las haciendas municipales y estatales. Participaciones que supuestamente están relacionadas con el concepto resarcitorio de los impuestos que dejarían de cobrar los Estados y Municipios, por entrar a un pacto federal. Hoy el Ramo 28 y sus Participaciones se componen de 13 fondos. De éstos, 5 no se distribuyen entre la totalidad de las Entidades Federativas. Ramo 33 : "Aportaciones a Entidades Federativas y Municipios".

Hasta antes de 1990, los gobiernos municipales no recibían de la Federación recursos para aplicar en obras y acciones sociales, bajo la modalidad de transferencias condicionadas. En ese contexto, sus finanzas dependían fundamentalmente de las participaciones fiscales, ya que sus ingresos propios eran sumamente reducidos. A partir de 1990 y hasta 1997, los municipios del país recibieron de la Federación recursos para el financiamiento de infraestructura social y servicios básicos para los grupos en pobreza extrema; los mecanismos programáticos utilizados para realizar esas 
transferencias tuvieron un espíritu compensatorio. A saber, Fondos Municipales de Solidaridad de 1990 a 1994; Fondo de Solidaridad Municipal, de 1994 a 1995 y Fondo de Desarrollo Social Municipal de 1996 a 1997. La extinta Secretaría de Programación y Presupuesto controlaba dichos fondos, posteriormente fue la Secretaría de Desarrollo Social. La normativa que regulaba su aplicación era federal, de alcance nacional y existía anualidad en el ejercicio de los recursos.

Con el fin de institucionalizar y dar certidumbre jurídica a estas transferencias, así como a otras destinadas a las entidades federativas, (con y para objetivos diversos), a fines de 1997, el Ejecutivo Federal envió a la Cámara de Diputados una iniciativa para modificar la Ley de Coordinación Fiscal (LCF), mediante la incorporación, a ese ordenamiento, de un Capítulo V, con el cual se constituirían las Aportaciones Federales para Entidades Federativas y Municipios. La iniciativa consideraba la creación original de 3 fondos: el Fondo de Aportaciones para la Educación Básica y Normal (FAEB),el Fondo de Aportaciones para los Servicios de Salud (FASSA), y el Fondo de Aportaciones para la Infraestructura Social Municipal (FAISM).La Cámara de Diputados determinó que se adicionaran otros tres fondos de Aportaciones, a los anteriores, que fueron: de Infraestructura Social Estatal (FAISE), que junto con el FAISM integraría el Fondo de Aportaciones para la Infraestructura Social (FAIS); otro para el Fortalecimiento de los Municipios y de las Demarcaciones Territoriales del Distrito Federal (FORTAMUN - DF); y el de Aportaciones Múltiples (FAM ), para transferir principalmente recursos a los DIF ya descentralizados a nivel estatal y a la educación. En 1999 se le agregan dos fondos más para complementar la descentralización de recursos en actividades educativas y de seguridad pública: el Fondo de Aportaciones para la 


\section{La Hacienda Pública Municipal}

Volumen 12, Número 22 ene-jun 2020

Emilio Margáin Manaotou

Educación Tecnológica y de Adultos (FAETA ), y el Fondo de Aportaciones para la Seguridad Pública (FASP). En 2007 se pasa

al Ramo 33 el Programa de Fortalecimiento a las Entidades Federativas ( PAFEF) que se ubicaba hasta 2006 en el Ramo 39. Queda así, el Ramo 33 con sus 8 fondos actuales. ... con fórmulas vigentes desde entonces y causando, con el paso de los años, distorsiones graves en las haciendas estatales y municipales." 8

\section{EXPOSICIÓN DE MOTIVOS DE REFORMA A LA LEY DE COORDINACIÓN FISCAL 2013}

Todo lo anterior motivó que para 2013 se enviara de nuevo, una propuesta de reforma a la Ley de Coordinación Fiscal en cuya Exposición de Motivos se menciona que

"las fórmulas actuales de transferencias del Sistema Nacional de Coordinación Fiscal, contenidas en la LCF, ( Ramos 33 y 28 ), han generado un sentimiento de insuficiencia de recursos en los tres órdenes de gobierno, con la idea generalizada de que el reparto es además, inequitativo. El hecho constatable o no, de que la federación es el ente más eficiente en materia recaudatoria, ha generado un círculo perverso de dependencia de los gobiernos locales, que limita su capacidad de acción frente a las necesidades reales de su población, porque se ha restringido su capacidad de financiarlos. Es común la queja de que los recursos impositivos propios son magros, como lo son las participaciones que reciben, lo cual les proporciona un culpable: la Federación. El esquema de suma cero, que contiene a la LCF, conlleva a que los cambios que

\footnotetext{
${ }^{8}$ www.diputados.gob.mx/LeyesBiblio/ref/lcf.htm
} 
históricamente se han propuesto, (de todo tipo y con seriedad), siempre generan estados ganadores y estados perdedores, y la salida más fácil ha sido que el costo de los perdedores, lo cargue la Federación.

En la situación actual de las finanzas federales, esto no es posible, sin que la Federación deje de cumplir con algunas de sus responsabilidades. En cualquier solución que se proponga, un problema es insoslayable: la falta de recursos públicos. Es sabido que la carga fiscal en nuestro país es de las más bajas del mundo, con esto, de no cambiar esquemas de fondo, no podremos financiar nuestro futuro desarrollo...

Y continúa la Exposición de Motivos precitada dando respuesta a sus propias interrogantes como se menciona enseguida :

\section{¿Por qué es importante modificar y actualizar la LCF ?}

Para RESARCIR a las Entidades Federativas y Municipios vía el retorno presupuestal monetario que aportan tributariamente al Presupuesto Federal, y esto se lleve a cabo con equidad $y$ transparencia.

Porque con el paso de los años, las 5 fórmulas contenidas en los primeros 4 capítulos de dicha Ley ( sin contar las de sus variables de medición), están obsoletas, distorsionan equilibrios inter estatales, demuestran inequidad e injusticias económicas entre lo que los Estados aportan al PIB y lo que la Federación les devuelve fiscalmente.

Porque de sus 13 fondos, que se han ido agregando de 1980 a la fecha, paulatina y de manera no transparente, no todos se reparten entre las 32 Entidades Federativas, originando injusticias geográficas y desequilibrios económicos.

Porque la LCF no contiene normas obligatorias de transparencia, permite reinterpretaciones locales, facilita la inclusión de variables inadecuadas de medición tributaria, y deja a los municipios en 


\section{La Hacienda Pública Municipal}

Volumen 12, Número 22 ene-jun 2020 Emilio Margáin Manaotou estado de indefensión fiscal. ${ }_{i \in E R E} E$ El objetivo del Fondo de Aportaciones para la Infraestructura Social Municipal (FAISM), es financiar obras y acciones sociales que beneficien directamente a la población en rezago social y pobreza extrema en los rubros programáticos definidos por la Ley de Coordinación Fiscal, que son: (10 etiquetas) isE Agua Potable, Alcantarillado, Drenaje y letrinas, Urbanización municipal, Electrificación rural y de colonias pobres, Infraestructura básica de salud, Infraestructura básica educativa, Mejoramiento de vivienda, Caminos rurales e Infraestructura productiva rural. financiamiento para la dotación de infraestructura y servicios básicos de cuando menos 1,700 municipios del país de tipo rurales y semiurbanos. Este fondo, es la principal vía para financiar obra pública, en virtud de la debilidad de las finanzas de los Ayuntamientos, inclusive, en muchos de esos municipios, sobre todo en los rurales, el FAISM es prácticamente la única fuente de financiamiento para ese fin. a los Municipios, vía el FAISM, en un período de 18 años (de 1996 a 2013), sumaron \$432,000 millones de pesos. Es importante señalar que en ese periodo, los siguientes Estados recibieron: Chiapas \$ 53,500 millones; Veracruz \$ 47,000 millones; Oaxaca \$ 40,000; y Guerrero \$34,000 millones, solo como ejemplo de los más financiados.

${ }_{i S E S P}^{i} D$ De lo anterior, puede observarse que ello ha beneficiado más a las entidades con menor grado de desarrollo, sin embargo, si bien los indicadores de infraestructura básica también han disminuido, lo cierto es que los grados de pobreza y pobreza extrema, según datos del Coneval, han crecido. istspetLas muchas fórmulas actuales de transferencias de la Ley de Coordinación Fiscal, a los Estados y Municipios, (Ramos 28 y 33), pero sobre todo la del FAISM, han generado grandes inestabilidades Financieras y de Planeación a los 
Estados y Municipios, y provocado el sentimiento de insuficiencia absoluta de recursos en los tres órdenes de gobierno, lo cual además, induce el sentimiento (real), de que el reparto es inequitativo....

\section{Fondo de Aportaciones para la Infraestructura Social}

El Fondo de Aportaciones para el Infraestructura Social ( FAIS ), se subdivide en 2 fondos ( FAISE y FAISM ), y está conformado con recursos federales equivalentes al 2.5 por ciento de la recaudación federal participable ( RFP ). Sin embargo, en 1998 el FAIS representó únicamente el 2.318 por ciento, y es hasta 1999 que los recursos representan el porcentaje establecido originalmente en la Ley de Coordinación Fiscal. Los dos fondos que lo componen se distinguen porque uno se integra a la hacienda estatal (FAISE), representando el $12.12 \%$ del total, mientras que el segundo (FAISM), se dirige a los municipios (87.88\%).EI FAISM proviene presupuestalmente del extinto Ramo 26 ( hoy Ramo 33 ), su distribución es mensual y se entrega en diez meses, lo que para muchos municipios implica un complicado esfuerzo de planeación y presupuestación.

Los recursos del fondo están etiquetados con base en actividades específicas, es decir, el fondo no puede usarse libremente por los municipios, sino que debe invertirse en diez tipos de obras básicas, ya señaladas. Para la distribución de estos recursos hacia los municipios, los estados pueden optar por 2 alternativas de cálculo: a ) utilizar la fórmula federal señalada en el artículo 34 de la Ley de Coordinación Fiscal, o en su caso, b) cuando los estados no puedan utilizar la fórmula de distribución federal para sus municipios, la ley exige que la distribución tome en cuenta los siguientes criterios básicos: a) Ingresos: al considerar la proporción de la población 


\section{La Hacienda Pública Municipal}

Volumen 12, Número 22 ene-jun 2020

Emilio Margáin Manaotou

municipal que perciba menos de dos salarios mínimos; b) Nivel educativo: con la proporción de la población municipal mayor de 14 años que no sepa leer y escribir; c) Vivienda: al tomar en cuenta la proporción de la población municipal que habite en viviendas particulares sin disponibilidad de drenaje conectado a fosa séptica $o$ a la calle; d) Electricidad: es decir la proporción de la población municipal que habite en viviendas particulares sin disponibilidad de electricidad. En 16 años de creado el FAISM en 1996 - 1998 ( Ramo 26 y 33 respectivamente), los municipios del país han recibido \$ 447,000 millones de pesos; y si a eso le aumentamos otros \$ 487,000 millones del Fondo 4 del mismo Ramo 33, denominado FAFOMUN, suman $\$ 934,000$ millones de pesos.

\section{¿Por que es necesario modificar y actualizar el Ramo 33 ?}

Porque en los últimos 14 años, se han transferido casi un BILLON de pesos a los municipios y la población en pobreza continúa creciendo.

Porque las 10 etiquetas actuales del FAISM, limitan la operación de los Alcaldes en materia de acciones para el desarrollo, y al ser exclusivas para obras de infraestructura, nunca se estará en condiciones de superar la pobreza económica de la población. Son objetivos distintos.

Porque las variables de la fórmula actual, ponderan la demografía en exceso, lo cual distorsiona las cualidades diferentes en la geografía municipal.

Porque desmotiva la eficiencia, ya que el Alcalde que va disminuyendo indicadores de pobreza, pierde recursos presupuestales anuales por eficacia. 
Porque los municipios urbanos, con más facilidades de obtener recursos propios, son los que se llevan montos mayores del FAISM. Porque la fórmula es discriminatoria, ya que un pobre de cualquier Estado e iguales condiciones de pobreza, puede recibir miles de pesos per cápita más, o menos, que otro de diferente Estado e igual condición.

Porque la fórmula no resiste análisis per cápita de ningún tipo, lo cual de sí misma la hace inequitativa e injusta.

Porque en 16 años de aplicar el FAISM a Estados y Municipios, en 6 años diferentes, los Estados y sus municipios han visto disminuido sus recursos considerablemente, pero, además, pueden pasar hasta 5 años, antes de recuperar el monto que les disminuyeron originalmente.

Porque dadas las condiciones actuales de la fórmula, ésta irá distorsionando más las puntas presupuestales entre municipios de igual condición de pobreza. Entre 2011 y 2012, 16 Estados y 1,261 municipios vieron disminuir sus recursos en más de $\$ 5,500$ millones de pesos.

Con lo anterior los alcaldes no pueden cumplir con 2 objetivos fundamentales: Hacer una planeación adecuada de sus prioridades de desarrollo; y menos aún aportar los muchos pari pasus ${ }^{9}$ que la Federación y los Estados le piden para obras.

Porque los municipios urbanos, dado el peso de la variables demográficas, siempre se llevarán la mayor parte de los recursos del FAISM.

${ }^{9}$ pari passu es un término utilizado en finanzas, bancos, títulos y valores financieros se establece como una cláusula en un contrato financiero para precisar que los créditos deberán de guardar las mismas igualdades de derechos y obligaciones en relación con otras deudas similares de un mismo emisor. El contrario de Pari passu sería: primero en tiempo, primero en derecho. http://www.eco-finanzas.com/diccionario/P/P.htm 


\section{La Hacienda Pública Municipal}

Volumen 12, Número 22 ene-jun 2020

Emilio Margáin Manaotou

Porque derivado de lo anterior, se beneficia doble e injustamente a dichos municipios muy urbanos con el Fondo 4 del Ramo 33 el FAFOMUN, que se reparte sin más criterio que la población municipal, y con qué objeto?

Porque la fórmula actual es complicada, inequitativa, distorsionante con el tiempo y los censos. Ya está rebasada, y no cumple ya con los principios de justicia y transparencia.

En 16 años, solo 8 Estados no han perdido recursos en algún año, los otros 24 hasta en 2 o 3 ocasiones. que la Comisión de Fortalecimiento al Federalismo, de esta $\mathrm{H}$. Cámara de Diputados XLII Legislatura, propone modificar diversos artículos de la LCF, referentes al Ramo 28 y la Fórmula del FAISM contenida en el Ramo 33, (artículos 34 y 35 de la LCF ), con los siguientes 6 objetivos y lineamientos:

1. Garantizar que al cambio de fórmulas, ningún Estado ni Municipio vea disminuidos sus recursos actuales, a partir de la entrada en vigor de estas modificaciones.

2. Tener por prioridad que los recursos se asignen equitativamente y con los objetivos que el Poder Legislativo les asignó de origen, esto es, fondos resarcitorios (Ramo 28) y compensatorios ( Ramo 33 ) a Estados y Municipios.

3. Presentar alternativas de fórmulas, que paulatinamente estimulen y fomenten el desarrollo y autonomía de los gobiernos locales, y la disminución de la pobreza, agregando indicadores sociales de eficiencia, evaluación $y$ transparencia.

4. Modificar las 10 etiquetas actuales del FAISM, que limitan las decisiones de los Gobiernos Locales.

5. Incluir en el articulado de la $L C F$, la sanciones necesarias que hasta ahora no tiene, para evitar reinterpretaciones normativas locales, coerciones programáticas, desvíos de 
recursos, la obligatoriedad del flujo de información y otras acciones de participación comunitaria y de transparencia.

6. Analizar la viabilidad de fusionar el Fondo 4 FAFOMUN con el FAISM en beneficio de los Municipios del país. "10

\section{EXPOSICIÓN DE MOTIVOS DE REFORMA A LA LEY DE COORDINACIÓN FISCAL 2014}

El 31 de octubre de 2013, fue aprobado por el Congreso de la Unión el paquete económico para el ejercicio fiscal de 2014, en cuya exposición de motivos se señala:

"Con fundamento en lo dispuesto por el articulo 71, fracción I, de la Constitución Política de los Estados Unidos Mexicanos, me permito someter por su digno conducto ante esa Honorable Asamblea, la presente Iniciativa de Decreto por el que se reforman, adicionan y derogan diversas disposiciones de la Ley de Coordinación Fiscal.

El Plan Nacional de Desarrollo 2013-2018 establece la necesidad de impulsar un federalismo articulado mediante una coordinación eficaz y una mayor corresponsabilidad de los tres órdenes de gobierno a fin de alcanzar los objetivos nacionales.

México requiere avanzar hacia un federalismo fiscal que coadyuve a establecer con claridad los ámbitos de competencia y responsabilidades de cada nivel de gobierno, a fin de preservar el

\footnotetext{
10 iniciativa de Decreto por el que se reforman y adicionan diversas disposiciones de la Ley de Coordinación Fiscal y de la Ley General de Contabilidad Gubernamental Contabilidad ...www3.diputados.gob.mx/camara/.../SCANN_iniciativa\%20_LCF.pdf ;reformas que Finalmente se publicaron en el DOF del 09 Diciembre de 2013 "DECRETO por el que se reforman y adicionan diversas disposiciones de la Ley de Coordinación Fiscal y de la Ley General de Contabilidad Gubernamental."

http://www.diputados.gob.mx/LeyesBiblio/ref/llf/LCF_ref34_09dic13.pdf [consultada el 15 de octubre de 2014]
} 


\section{La Hacienda Pública Municipal}

Volumen 12, Número 22 ene-jun 2020

Emilio Margáin Manaotou

equilibrio de las finanzas públicas y optimizar el ejercicio y control del gasto público en los tres ámbitos de gobierno que redunde en mejores condiciones de vida para los mexicanos. El fortalecimiento del federalismo fiscal constituye uno de los ejes de la reforma hacendaria, tal como se proyecta en el Compromiso 70 del Pacto por México "Fortalecimiento del Federalismo Fiscal".

En ese sentido, la presente Iniciativa recoge los principales planteamientos formulados por los funcionarios fiscales en el marco del Sistema Nacional de Coordinación Fiscal; de aquéllos derivados del diálogo entre el Gobierno Federal, las entidades federativas y los municipios; de la Conferencia Nacional de Gobernadores, y los de las diferentes dependencias federales encargadas de administrar y fiscalizar los Fondos de Aportaciones Federales, a fin de adecuar el federalismo hacendario a la realidad nacional. La presente iniciativa que se somete a consideración de ese Congreso de la Unión propone, se basa principalmente en tres objetivos:

1. Fortalecer la capacidad financiera de los tres órdenes de gobierno, a través de robustecer los incentivos recaudatorios

2. de las entidades federativas y municipios que se otorgan mediante los Fondos de Participaciones Federales.

3. Mejorar la distribución, el destino y el ejercicio de los recursos de los Fondos de Aportaciones Federales, a fin de reforzar los objetivos para los que fueron creados; y así asegurar un mejor uso de los recursos, una mayor transparencia en la distribución a las entidades federativas y municipios y, una mayor predictibilidad en los mismos para facilitar la planeación.

4. Apoyar a los municipios del país para alcanzar y mantener finanzas públicas sanas, mediante la implementación de un sistema de estímulos y esquemas dirigidos a garantizar los 
pagos en materia de aguas nacionales y el fortalecimiento de la recaudación del impuesto predial.

Al respecto, es importante destacar que las mejoras propuestas para la distribución de los recursos no reducirán el valor nominal de las transferencias actuales globales para ninguna entidad federativa.

\section{Participaciones Federales}

México es uno de los países de la Organización para la Cooperación y el Desarrollo Económico (OCDE) con menor nivel de recaudación subnacional ya que ésta representa únicamente el $0.7 \%$ del Producto Interno Bruto (PIB) considerando los ingresos tributarios locales de las entidades federativas y los municipios. El promedio de la recaudación de los gobiernos locales en los demás países que forman parte de dicha Organización es de $8.9 \%$ del PIB ${ }^{11}$ Aun si se considera solo la región de América Latina, el nivel observado en nuestro país es bajo ya que los ingresos propios de los gobiernos de las entidades federativas y municipios en la región ascienden a 2.3\% del PIB, poco más de 3 veces lo observado en México.

Por otra parte, en relación con la distribución de participaciones, la Ley de Coordinación Fiscal vigente contempla un esquema de incentivos asociado a los niveles e incrementos observados en la recaudación local. Con base en estos criterios, el Fondo General de Participaciones (427 mil millones de pesos en 2013, en adelante mmp) reparte $13 \%$ de los recursos, y los Fondos de Fomento Municipal (21 mmp en 2013) y de Fiscalización (26 mmp en 2013), distribuyen $31 \%$.

\footnotetext{
11 Promedio de Países seleccionado en América Latina por la OCDE
} 


\section{La Hacienda Pública Municipal}

Volumen 12, Número 22 ene-jun 2020

Emilio Margáin Manaotou

No obstante lo anterior, dados los bajos niveles de recaudación local, resulta necesario reforzar este incentivo, el cual debe de ir acompañado de una medición más precisa de los ingresos propios locales que permita cuantificar de manera más puntual los recursos efectivamente cobrados por parte de las entidades federativas y municipios. Asimismo, se propone ajustar la estructura de la distribución de forma consistente con los cambios tributarios contenidos en la presente propuesta, así como en las iniciativas que conforman la Reforma Social y Hacendaria.

Por otra parte, en la presente Iniciativa se plantea fortalecer los incentivos recaudatorios que deben tener las Participaciones

Federales, tanto a nivel estatal como municipal, mediante las propuestas que se mencionan a continuación:

1. Se sustituye el "Fondo de Fiscalización" por el "Fondo de Fiscalización y Recaudación". Los recursos de dicho Fondo seguirán siendo equivalentes al $1.25 \%$ de la recaudación federal participable de cada ejercicio y su fórmula de distribución considerará algunas variables de la fórmula actual del Fondo de Fiscalización, a saber: i) las cifras virtuales de la entidad de que se trate, que dé a conocer el Servicio de Administración Tributaria; ii) el valor de la mercancía embargada o asegurada por cada entidad que dé a conocer el Servicio de Administración Tributaria, y iii) la última información oficial de población que dé a conocer el Instituto Nacional de Estadística y Geografía (INEGI) para cada entidad. Adicionalmente, se incorporan las variables de "ingresos de libre disposición" y "recaudación de impuestos y 
derechos locales" para incentivar la recaudación de estos últimos y fortalecer las haciendas públicas locales. La propuesta de incorporación de estas variables obedece adicionalmente a la propuesta de derogación del Régimen de Pequeños Contribuyentes e Intermedios que se incluye en la iniciativa de Decreto por el que se expide la Ley del Impuesto sobre la Renta que integra, junto con la presente iniciativa, la Reforma Hacendaria y de Seguridad Social.

2. La distribución del Fondo General de Participaciones hacia los municipios deberá atender criterios similares a los que usa la Federación para distribuir las Participaciones

Federales a las entidades federativas; es decir, criterios que fomenten la actividad económica y estimulen la recaudación. Lo anterior, permitirá lograr una sinergia recaudatoria nacional que coadyuvará al fortalecimiento de las haciendas públicas locales y a una actividad económica más dinámica. Para mejorar la distribución de los recursos del Fondo General de Participaciones es necesario garantizar la uniformidad de la información que se usa para tal efecto. En ese sentido, sólo se considerará el flujo de efectivo de los importes recaudados de los impuestos y derechos locales, incluido el impuesto predial y los derechos por suministro de agua, mismos que se informarán en los formatos que emita la Secretaría de Hacienda y Crédito Público. Asimismo, se excluyen los ingresos vinculados con el otorgamiento de beneficios, programas, subvenciones o subsidios dirigidos a determinado sector de la población o de la economía. Adicionalmente, sólo se considerará como recaudación de derechos aquellas 


\section{La Hacienda Pública Municipal}

Volumen 12, Número 22 ene-jun 2020

Emilio Margáin Manaotou

contribuciones por el uso o aprovechamiento de los bienes del dominio público de las entidades, así como por los servicios que presten en sus funciones de derecho público, lo cual está en línea con lo establecido en el Código Fiscal de la Federación, excepto cuando se presten por organismos descentralizados u órganos desconcentrados. No obstante, se considerarán los derechos a cargo de los organismos públicos descentralizados que presten servicios exclusivos del Estado.

Para el cálculo de la recaudación federal participable, se propone establecer que no se incluirá el impuesto sobre la renta (ISR) causado por los trabajadores de la Federación, de las entidades federativas y de los municipios. Lo anterior, en virtud de que las entidades recibirán en su totalidad el mencionado impuesto causado por los empleados de los gobiernos subnacionales, siempre y cuando el salario sea efectivamente pagado por los entes mencionados. Dicha propuesta atiende a la petición de las entidades federativas, formulada a través de la Comisión Permanente de Funcionarios Fiscales, en el sentido de que dicho gravamen sea cien por ciento participable a las propias entidades federativas, en los montos que correspondan a los servidores públicos estatales y municipales.

Adicionalmente, se propone que la aplicación de este criterio, se llevará a cabo de forma simultánea con la implementación de un nuevo esquema de financiamiento educativo, es por ello que se plantea prever mediante una disposición transitoria que la entrada en vigor de esta propuesta será un año después de la entrada en 
vigor de las reformas que mediante esta iniciativa se someten a consideración de ese Congreso de la Unión.

Por otra parte, es necesario mencionar respecto del impuesto predial, que México es el país de la OCDE con el menor nivel de recaudación ya que esta representa sólo el $0.2 \%$ del PIB nacional, mientras que el promedio de la recaudación en los países que integran dicha Organización es de $1.1 \%$ del PIB. La recaudación es superior incluso en otros países con un nivel de desarrollo similar al nuestro. Por ejemplo, en Chile la recaudación de dicha contribución alcanza $0.6 \%$ de su PIB. Por lo anterior, es necesario buscar

alternativas para cambiar la situación descrita, contribuyendo al fortalecimiento de los ingresos de los municipios, por lo que en la presente Iniciativa se propone aprovechar las ventajas comparativas y las economías de escala de las entidades federativas, a través de su estructura administrativa y recaudatoria, a fin de que se establezcan medidas que permitan potenciar el cobro del impuesto predial.

En ese sentido, se plantea modificar la fórmula del Fondo de Fomento Municipal con el objeto de incentivar a que las entidades federativas puedan asumir, mediante la firma de convenios, la operación del cobro del impuesto predial de sus municipios, con la finalidad de incrementar la eficacia en el mismo. Cabe destacar que un impuesto predial diseñado adecuadamente tiende a ser altamente progresivo, siendo proporcionalmente mayor para propiedades de mayor valor. 


\section{La Hacienda Pública Municipal}

Volumen 12, Número 22 ene-jun 2020

Emilio Margáin Manaotou

La fórmula propuesta garantiza que las entidades recibirán el mismo monto que recibieron de dicho Fondo en 2013, mientras que el excedente se distribuirá en un $70 \%$ conforme a los criterios actuales y el $30 \%$ restante, con base en el porcentaje que represente el incremento en la recaudación del impuesto predial, respecto de la misma en el total de las entidades que tengan la responsabilidad del cobro del tributo en mención.

Con esta nueva fórmula se advierten los siguientes beneficios para los municipios: i) mayores ingresos propios por el incremento esperado en la recaudación; ii) más ingresos derivados del Fondo

de Fomento Municipal; iii) una participación más elevada de los recursos del Fondo General de Participaciones, como consecuencia del incremento en la recaudación, y iv) menores costos de administración del impuesto, mismos que se absorberán por las entidades federativas aprovechando las economías de escala y sinergias presentes en ese orden de gobierno.

Por último, se considera conveniente proponer el establecimiento de un Fondo de Estabilización de los recursos que corresponden a las entidades federativas por concepto del Fondo de Extracción de Hidrocarburos (FEXHI). En términos generales, los fondos de estabilización constituyen una forma de acumular recursos que permite a los gobiernos compensar las posibles caídas en los ingresos públicos y evitar la afectación consecuente sobre el gasto público.

El Fondo de Estabilización que se propone, se alimentará con un porcentaje determinado de los ingresos excedentes del FEXHI, respecto de lo estimado y calendarizado anualmente. Dicho Fondo 
de Estabilización tendrá por finalidad compensar la disminución en la ministración de los recursos obtenidos por el FEXHI respecto de la estimación y calendarización referida. Las entidades federativas que reciben recursos del FEXHI podrán participar en el mismo de manera voluntaria.

\section{ACTUALIZACIÓN DE LA LEY DE COORDINACIÓN FISCAL}

En la presente iniciativa se propone derogar la disposición que prevé un destino específico para los recursos que reciben las entidades federativas derivadas de las cuotas aplicadas a la venta

final de gasolina y diésel, así como aquellas disposiciones relacionadas. Lo anterior deviene de la Acción de Inconstitucionalidad 29/2008 resuelta por el Pleno de la Suprema Corte de Justicia de la Nación, declarando la invalidez respecto de señalar un destino específico a los recursos referidos.

Asimismo, se plantea reformar el artículo 40-A de la Ley de Coordinación Fiscal, acorde con la propuesta presentada para modificar la Ley del Impuesto Especial sobre Producción y Servicios, por el que Petróleos Mexicanos se convierte en sujeto pasivo del impuesto aplicable a las gasolinas y al diesel. En ese sentido, los recursos que corresponden a las entidades federativas (9/11), se entregarán con base en la información que Petróleos Mexicanos proporcione a la Secretaría de Hacienda y Crédito Público.

De igual manera, se elimina la referencia que señala que las entidades federativas reintegrarán a la Federación los 2/11 de los recursos referidos para conformar el Fondo de Compensación, toda vez que la Secretaría de Hacienda y Crédito Público recibirá el pago 


\section{La Hacienda Pública Municipal}

Volumen 12, Número 22 ene-jun 2020

Emilio Margáin Manaotou

de dichas contribuciones directamente de Petróleos Mexicanos para

conformar el Fondo mencionado, el cual distribuirá a las entidades federativas dentro del mes siguiente al entero de dichas cantidades por parte de Petróleos Mexicanos. Es relevante destacar que las modificaciones propuestas no llevarán a un incremento en el precio de los combustibles para el consumidor final con respecto de los niveles observados en la actualidad.

Adicionalmente se plantea adicionar la responsabilidad de los estados de publicar en sus periódicos oficiales los recursos correspondientes a sus municipios, y en el caso del Distrito Federal los de sus demarcaciones territoriales, por las contribuciones en mención.

\section{SISTEMA NACIONAL DE COORDINACIÓN FISCAL}

Con la entrada en vigor de la Ley de Coordinación Fiscal en 1980, se creó el Sistema Nacional de Coordinación Fiscal, con el objetivo de eliminar las situaciones de desequilibrio e inequidad existentes en materia de distribución del ingreso fiscal entre los tres órdenes de gobierno.

En el Capítulo IV de la Ley de Coordinación Fiscal vigente se relacionan los organismos a través de los cuales la Secretaría de Hacienda y Crédito Público y las entidades federativas participarán en el desarrollo, vigilancia y perfeccionamiento de dicho Sistema:

1. La Reunión Nacional de Funcionarios Fiscales.

2. La Comisión Permanente de Funcionarios Fiscales.

3. El Instituto para el Desarrollo Técnico de las Haciendas Públicas. 


\section{La Junta de Coordinación Fiscal.}

Además, existen grupos técnicos y de trabajo que fueron creados en el seno de la Comisión Permanente de Funcionarios Fiscales, para llevar a cabo el análisis, estudios y formulación de propuestas en el marco del federalismo fiscal, así como para dar seguimiento a los temas correspondientes y vigilar el correcto funcionamiento del Sistema Nacional de Coordinación Fiscal. Los trabajos que llevan a cabo dichos grupos son de gran importancia, ya que a partir de los

acuerdos que ahí se alcanzan, se toman decisiones trascendentales para las políticas públicas de las entidades federativas. En ese sentido, con el objetivo de incrementar la Transparencia y el orden de esos trabajos, se propone facultar a la Reunión Nacional de Funcionarios Fiscales para aprobar las reglas, reglamentos 0 lineamientos que estos grupos deberán observar, en su funcionamiento, operación y compromisos para el desarrollo de las funciones que en materia de coordinación fiscal ejercen.

Derivado de los constantes cambios en nuestro país, es necesario que los grupos mediante los cuales se otorga representación a las entidades federativas en el Sistema Nacional de Coordinación Fiscal compartan intereses, problemáticas y objetivos comunes. Por lo anterior, se plantea incorporar la posibilidad de que la Comisión Permanente de Funcionarios Fiscales pueda proponer una reclasificación de manera unánime de los ocho grupos a través de los cuales son representadas todas las entidades federativas del país. Dicha reclasificación podrá realizarse cada 10 años, con base en un análisis de las características sociodemográficas y geográficas de las entidades. 


\section{La Hacienda Pública Municipal}

Volumen 12, Número 22 ene-jun 2020

Emilio Margáin Manaotou

Para contribuir al fortalecimiento de los municipios de México, se contempla la incorporación de la visión municipal en las actividades que se realicen en los trabajos de la Comisión Permanente de Funcionarios Fiscales. Para tal efecto, se propone incluir al Presidente de la Conferencia Nacional de Municipios de México (CONAMM) como invitado permanente a las reuniones de los Funcionarios Fiscales de la referida Comisión.

\section{Fondos de Aportaciones Federales}

Las aportaciones federales surgieron como un mecanismo redistributivo de recursos con un destino específico de gasto que al interactuar con las participaciones federales permite que aquellas entidades con rezago económico se vean beneficiadas en mayor medida con recursos federales, sin desincentivar el crecimiento y esfuerzo recaudatorio.

La presente Iniciativa propone modificar la forma de distribución del Fondo de Aportaciones para la Infraestructura Social (FAIS).

Actualmente, el FAIS se distribuye en función de la pobreza extrema a nivel nacional, mediante la fórmula del Índice Global de Pobreza, el cual se compone por cinco brechas de las necesidades básicas: ingreso por persona, nivel educativo promedio por hogar, disponibilidad de espacio en la vivienda, disponibilidad de drenaje y disponibilidad de electricidad-combustible para cocinar.

La fuente de información utilizada para la distribución del Fondo es la base de datos de la Muestra Censal (cuestionario ampliado) de los Censos de Población y Vivienda que realiza el INEGI, los cuales 
se actualizan cada diez años. Si bien el uso de información censal conduce a una mayor precisión en la medición, esto origina un rezago en el reconocimiento de los cambios en las variables consideradas, además de generar variaciones abruptas en los recursos que reciben los estados cuando tiene lugar la actualización, como ocurrió en 2012. Igualmente, la distribución del Fondo se basa en criterios altamente correlacionados con pobreza

y rezago, pero que no están vinculados de forma unívoca con estos conceptos.

Para atender la problemática del FAIS se plantea a esa Soberanía una actualización de la fórmula a partir del incremento en recursos esperado para 2014, la cual esté basada en fuentes de información más oportunas; que se distribuya con base en indicadores directos de pobreza extrema y rezago social, y que tenga un componente que premie la reducción de la pobreza. La actualización de la fórmula permitirá canalizar los recursos atendiendo plenamente el objetivo del Fondo. La medición más oportuna obedecerá al uso de estadísticas de carencias de la población en pobreza extrema publicadas por el Consejo Nacional de Evaluación de la Política de Desarrollo Social, información que se deriva del Módulo de Condiciones Socioeconómicas de la Encuesta Nacional de Ingreso y Gasto de los Hogares que realiza el INEGI bianualmente (cada 5 años en el caso de los municipios) y, por otro lado, permitirá suavizar la transición de los estados que cumplan con el abatimiento eficiente de las carencias en la población. 


\section{La Hacienda Pública Municipal}

Volumen 12, Número 22 ene-jun 2020 Emilio Margáin Manaotou

Se propone mejorar la formula de distribución de los recursos atendiendo a tres componentes:

1. El numero promedio de carencias de la población en pobreza extrema, que por su composición permitirá medir con mayor precisión la intensidad de la pobreza, otorgando mayores recursos a las entidades federativas con pobreza y rezago social.

2. Eficacia en la reducción de la pobreza extrema. Dicho componente busca premiar a las entidades federativas que

focalizan los recursos del Fondo adecuadamente, lo cual se refleja en la disminución de la cantidad de personas en pobreza extrema y la superación de la situación de rezago social de la población.

3. Con la finalidad de evitar una afectación a los objetivos de reducción de la pobreza en las entidades federativas por la nueva formula que se propone, se garantiza un monto fijo equivalente al importe que cada entidad recibió en 2013.

La premisa fundamental al realizar las modificaciones planteadas es que ninguna entidad federativa pierda recursos, lo anterior en virtud de que se pretende que todas las entidades federativas reciban cuando menos el valor nominal de las transferencias del ano 2013 y la nueva formula de distribución del Fondo solo se aplicará a las cantidades que excedan el valor nominal de dicho ejercicio fiscal.

Fortalecimiento de la transparencia en la distribución, destino y ejercicio de los Fondos de Aportaciones

Para coadyuvar al fortalecimiento de la transparencia en los mecanismos de distribución de las Aportaciones Federales, así 
como de su destino y ejercicio, se propone que todas las dependencias federales responsables de los Fondos de Aportaciones den a conocer en el Diario Oficial de la Federación las formulas y variables de distribución de los recursos.

Por otro lado, para contribuir al fortalecimiento de las haciendas municipales, se somete a consideración de esa Soberanía otorgar la posibilidad de destinar los recursos del Fondo de Aportaciones

para el Fortalecimiento de los Municipios y Demarcaciones Territoriales del Distrito Federal a la modernización de los sistemas de recaudación locales.

Con el objetivo de hacer más eficiente el ejercicio de los recursos, se propone que los gobiernos de las entidades federativas deberán transferir a los ejecutores del gasto, los recursos que reciban de la federación por concepto de los Fondos de Aportaciones Federales, en un plazo máximo de cinco días naturales.

En materia de seguridad público se precisa y se actualizan los términos del destino de los recursos del Fondo de Aportaciones para la Seguridad Pública de los Estados y del Distrito Federal. Asimismo, para fortalecer y contar con un mejor y oportuno ejercicio del gasto, se establece un margen de modificación al programa de gasto de los recursos del Fondo previa justificación y aprobación del Consejo Estatal de Seguridad Pública correspondiente, o la opinión favorable del Secretariado Ejecutivo del Sistema Nacional de Seguridad Pública, con la finalidad de lograr una efectiva y eficiente planeación, programación y presupuestación de las estrategias y acciones a realizar en materia de seguridad pública, ya que en la actualidad las 


\section{La Hacienda Pública Municipal}

Volumen 12, Número 22 ene-jun 2020

Emilio Margáin Manaotou

entidades federativas realizan modificaciones significativas a su

programa original, lo que genera elevados subejercicios en el manejo de este fondo.

En relación con el Fondo de Aportaciones para la Infraestructura Social, se establece la obligación para las entidades federativas y municipios de presentar informes relacionados con el uso de los

recursos a las Delegaciones Estatales de la Secretaría de Desarrollo Social y a la Secretaría de Hacienda y Crédito Público.

\section{Destino de los recursos}

La reducción de la pobreza como uno de los principales objetivos de este Gobierno, es de suma importancia que los recursos federales que se destinan a este rubro se orienten a acciones para fortalecer la atención a la población en dicha situación, así como a obras de alto impacto social que beneficien a los segmentos más pobres de la sociedad.

En tal virtud, con el objetivo de que los receptores de los recursos del Fondo de Aportaciones para la Infraestructura Social, cuyo objetivo es beneficiar a la población en pobreza extrema, ejerzan los recursos de forma más eficiente para atender las carencias de la población y con la posibilidad de potenciar su incidencia en el abatimiento de las mismas, en la presente iniciativa se propone establecer como obligación de la Secretaría de Desarrollo Social publicar un Informe anual sobre la situación de pobreza y rezago social de los estados y sus respectivos municipios, con base en lo que establece la Ley General de Desarrollo Social para la medición de la pobreza. 
En este sentido, el Informe mencionado en el párrafo que antecede servirá como una guía indicativa para que los estados y municipios puedan determinar las obras y acciones prioritarias a realizar con los recursos del citado Fondo. Adicionalmente, a fin de establecer con claridad el destino de los recursos del Fondo, se enlistan los mismos en grandes rubros, y se detallarán en el catálogo de acciones de los Lineamientos que para tal efecto emita la Secretaría de Desarrollo Social.

Asimismo, se propone establecer que dicha dependencia deberá proporcionar capacitación, a los estados y sus respectivos municipios, sobre el funcionamiento del Fondo de Aportaciones para la Infraestructura Social Municipal, el Fondo de Aportaciones para la Infraestructura Social Estatal y el Programa de Desarrollo Institucional Municipal, con la finalidad de obtener mejores resultados en la aplicación de los recursos.

Las carencias de infraestructura, así como las diferencias que existen entre las entidades federativas en su nivel de desarrollo obligan a realizar esfuerzos para consolidar instrumentos de financiamiento para proyectos de infraestructura que contribuyan a su desarrollo. En este sentido, se tiene como objetivo de política pública promover la participación de las entidades federativas para realizar acciones de mejoramiento y la ampliación de infraestructura física en los mismos, las cuales presentan rezagos y desigualdades significativas. El Fondo de Aportaciones Múltiples y Fondo de Aportaciones para la Seguridad Pública de los Estados y del Distrito Federal tienen entre sus destinos de gasto, la realización de infraestructura educativa y de seguridad, respectivamente:

- Los recursos del Fondo de Aportaciones Múltiples pueden emplearse para la construcción, equipamiento y rehabilitación 


\section{La Hacienda Pública Municipal}

Volumen 12, Número 22 ene-jun 2020

Emilio Margáin Manaotou

de infraestructura física de los niveles de educación básica, media superior y superior en su modalidad universitaria.

- Los recursos del Fondo de Aportaciones para la Seguridad Pública de los Estados y del Distrito Federal, pueden emplearse para la construcción, mejoramiento o ampliación de las instalaciones para la procuración e impartición de justicia, de los centros de readaptación social, así como de las instalaciones de los cuerpos de seguridad pública y de sus centros de capacitación.

Actualmente, los recursos de los Fondos referidos que se destinan a infraestructura física se pulverizan en varios proyectos que en su conjunto tienen un menor impacto social al que podría alcanzarse con un programa integral de inversiones, vinculado con la política nacional en materia de infraestructura educativa y de seguridad pública.

Así, con la finalidad de enfocar el gasto en obras en infraestructura educativa y de seguridad pública con un alto impacto social, se plantea a esa Honorable Asamblea contemplar dentro de la Ley de Coordinación Fiscal la posibilidad de que los Fondos señalados que correspondan a las Entidades Federativas, puedan afectarse para garantizar obligaciones en caso de incumplimiento, o servir como fuente de pago de obligaciones que se contraigan en términos de los convenios que celebren con la Federación, a través de la Secretaría de Hacienda y Crédito Público, con el objetivo de potenciar la inversión en infraestructura en los campos referentes a dichos Fondos.

\section{Regularización del cobro de agua a los municipios}


En el artículo 51 del ordenamiento que nos ocupa se establece que los recursos del Fondo de Aportaciones para el Fortalecimiento de los Municipios y de las Demarcaciones Territoriales del Distrito Federal (FORTAMUN) pueden afectarse para cubrir los adeudos de los municipios por concepto de derechos y aprovechamientos de agua, cuando así lo dispongan las leyes locales. Durante 2007 se otorgó un esquema de incentivos para disminuir los adeudos en materia de agua de los Organismos Municipales y Estatales a la Comisión Nacional del Agua (CONAGUA), a cambio de una regularización en el pago futuro a través del otorgamiento de la garantía de pago del FORTAMUN. Esto trajo consigo que 267 municipios se adhirieran al esquema y la CONAGUA incrementara su recaudación y, con ello, sus inversiones.

A la fecha, los adeudos de organismos de agua municipales y estatales siguen siendo significativos: UN total de $105 \mathrm{mmp}$, de los cuales, $80 \mathrm{mmp}$ son municipales (alrededor del $75 \%$ de las participaciones anuales que le corresponden a los municipios). Es importante reconocer la inviabilidad existente para cubrir dicho monto y lo importante que es generar una dinámica de cobro y pago hacia adelante.

Para todos aquellos municipios integrantes de las entidades en cuya legislación se haya establecido dicha opción, se abre la posibilidad de regularizar sus pagos y disminuir sus adeudos, ya sea a través de las retenciones que efectúe la entidad federativa a los recursos que les correspondan del Fondo de Aportaciones en comento o por pagos espontáneos que realicen.

De tal forma, la Comisión Nacional del Agua podrá mejorar su recaudación y con ello realizar inversión en infraestructura que permita abatir el rezago en este sector. 


\section{La Hacienda Pública Municipal}

Volumen 12, Número 22 ene-jun 2020

Emilio Margáin Manaotou

Para no afectar el destino programado de los recursos del FORTAMUN que los municipios tienen previsto recibir durante su administración, la posible afectación de dichos recursos se realizará con incrementos graduales anuales, en tal virtud, en la presente iniciativa se propone iniciar con un límite de afectación de al menos el $50 \%$ del Fondo.

Actualmente, no se especifica en el destino de los recursos del citado Fondo, el concepto de "descargas de aguas residuales". En ese sentido, se propone su adición al artículo 37 y 51 de la Ley que nos ocupa, para expresarlo de manera precisa y que los municipios también puedan regularizar los pagos por este concepto, ya que actualmente los adeudos en este rubro representan alrededor del 90\% del adeudo total con la Comisión Nacional del Agua.

\section{Financiamiento bursátil}

Actualmente, sólo 14\% del total de la deuda de entidades federativas y municipios es colocada en el mercado bursátil, del cual la mitad tiene como fuente de pago participaciones. Una limitante para que el mercado bursátil sea una opción para el financiamiento que contratan las entidades con fuente de pago de participaciones, es el no poder instrumentar el vehículo de pago con la fuente de participaciones direccionada al mismo antes de la realización de la emisión.

Para incentivar que se emplee de forma más dinámica el mercado bursátil en el financiamiento subnacional y con ello, las entidades tengan una opción adicional para obtener recursos en las mejores condiciones posibles, se propone incluir la disposición de permitir afectar participaciones e inscribir en el Registro de Obligaciones y Empréstitos de Entidades Federativas y Municipios a un vehículo 
cuya obligación bursátil no se haya formalizado jurídica ni financieramente. Cabe destacar que hay otros beneficios al realizar operaciones a través del mercado bursátil, como la posibilidad de realizar licitaciones, una mayor transparencia y una mayor información sobre las condiciones de financiamiento reflejadas en el precio de los activos en el mercado secundario.

Por otra parte, para evitar distorsiones en las afectaciones, se otorgará un plazo preventivo para realizar la operación de financiamiento de diez días hábiles, en el entendido que de no hacerse la oferta en el plazo señalado, se procederá a la cancelación de la inscripción en dicho Registro y la afectación respectiva. Tratándose de emisiones al amparo de fideicomisos o cualquier otro vehículo, cuya garantía o fuente de pago sean las participaciones, para acreditar la existencia de una obligación, bastará con que se presente evidencia de que el objeto de oferta pública e intermediación en el mercado de valores se encuentran inscritos en el Registro Nacional de Valores a cargo de la Comisión Nacional Bancaria y de Valores. Se especifica que las participaciones que correspondan a las entidades y municipios que pueden afectarse para el pago de obligaciones, son las que corresponden al Fondo General de Participaciones y al Fondo de Fomento Municipal. Esta precisión hace más eficiente la instrumentación de la afectación de participaciones y, adicionalmente, dichos fondos son los de mayor peso en el total de las participaciones, representando más del $90 \%$ del total de las mismas y, por lo tanto, son suficientes para cubrir el pago de obligaciones. Adicionalmente, el acotamiento del uso, es correcto ya que no todas las participaciones son susceptibles de ser afectadas. 


\section{La Hacienda Pública Municipal}

Volumen 12, Número 22 ene-jun 2020

Emilio Margáin Manaotou

El juicio que emita la Secretaría de Hacienda y Crédito Público respecto del registro de las obligaciones de los municipios cuando no cuenten con la garantía solidaria de la entidad correspondiente, se hará con base en lo establecido en el Reglamento del Artículo 9o. de la Ley de Coordinación Fiscal en Materia de Registro de Obligaciones y Empréstitos de Entidades Federativas y Municipios.

Asimismo, para contribuir con la transparencia en la materia, se establece la necesidad de que el Registro de Obligaciones y Empréstitos de Entidades y Municipios que lleva la Secretaría de Hacienda y Crédito Público sea público y permita la identificación del porcentaje total de participaciones federales afectadas por cada Entidad y Municipio, así como el destino definido en el propio documento que formaliza la obligación de la entidad.

\section{Actualización de la Terminología}

Con la finalidad de que las entidades federativas y los municipios puedan ejercer el gasto adecuadamente y la fiscalización de los recursos sea más eficiente, es necesario clarificar algunos conceptos ambiguos que dificultan su correcto entendimiento y conllevan a una mala focalización de los recursos; asimismo, se actualizan algunos conceptos por modificaciones de naturaleza diversa.

La imprecisión del concepto "asistencia social" del Fondo de Aportaciones Múltiples genera heterogeneidad en la aplicación de los recursos de dicho Fondo entre las entidades federativas, lo cual es susceptible de observaciones en la fiscalización de los recursos. Por lo tanto, se señala que dicho concepto se entenderá conforme a la Ley de Asistencia Social la cual se refiere, entre otros aspectos, a los sujetos susceptibles de recibir apoyo y a las acciones de 
asistencia social, respectivamente. En relación con el Fondo de Aportaciones para la Seguridad Pública de los Estados y del Distrito Federal, se actualiza la referencia terminológica en virtud de la desaparición de la Secretaría de Seguridad Pública.

Actualmente, los estados y municipios presentan dificultades para focalizar adecuadamente los recursos del Fondo de Aportaciones para la Infraestructura Social debido a la poca claridad de los conceptos "sectores de pobreza extrema y de rezago social". Asimismo, genera complejidad para comprobar que los recursos se están destinando a dichos "sectores". En ese sentido, se propone sustituir tales términos, para especificar que los recursos se destinarán a la "población en pobreza extrema, localidades con alto o muy alto nivel de rezago social conforme a lo previsto en la Ley General de Desarrollo Social, y en las zonas de atención prioritaria".

Lo mismo ocurre con el término "intermunicipal" en el caso de los recursos del Fondo de Aportaciones para la Infraestructura Social Estatal. Al respecto, se propone modificar la redacción, para que se especifique que dichos recursos deberán beneficiar a "población de los municipios y localidades que presenten mayores niveles de rezago social y pobreza extrema en el Estado".

A efecto de evitar que los recursos que reciban las entidades y municipios por concepto de Aportaciones Federales sean considerados como ingresos propios, se elimina dicha posibilidad del artículo 49 de la Ley, por lo que sólo deberán registrarlos en sus respectivas leyes de ingresos y destinarlos a los fines establecidos.

En la presente iniciativa se pretende establecer que los coeficientes C2 y C3 de la fórmula de distribución del Fondo General de Participaciones sean incentivos recaudatorios, para futuras 


\section{La Hacienda Pública Municipal}

Volumen 12, Número 22 ene-jun 2020

Emilio Margáin Manaotou

referencias en la propia Ley. En consecuencia a la modificación

propuesta de la fórmula de distribución de los recursos del Fondo de Aportaciones para la Infraestructura Social, se plantea eliminar la fórmula alternativa establecida en el artículo 35 de la Ley en cuestión, pues la misma no considera la profundidad de la pobreza extrema. Cabe señalar que la Secretaría de Desarrollo Social establece convenios con las entidades respecto de la distribución del Fondo a nivel municipal, por lo que las entidades cuentan con el respaldo de dicha Secretaría para la aplicación correcta de la fórmula." 12

Por su parte, el Presidente del Banco Interamericano de Desarrollo BID Luis Alberto Moreno ${ }^{13}$, atinadamente señala que "aunque hay una gran heterogeneidad en los sistemas tributarios de la región,.. las reformas tributarias para el desarrollo inclusivo que requieren nuestros países deben respetar cinco principios básicos:

En primer lugar, las reformas deben incluir impuestos que favorezcan a los pobres. ${ }^{14}$

En segundo lugar, las reformas deben establecer sistemas fiscales más sencillos con bases tributarias más amplias. ${ }^{15}$

\footnotetext{
12 http://www.diputados.gob.mx/PEF2014/ingresos/11_lcf.pdf

${ }_{13}$ Moreno, Luis Alberto, Recaudar no basta: Los Impuestos como Instrumento de Desarrollo, Ed.,BID,2012.pp 32

14 La primera prioridad es mejorar la progresividad de los sistemas fiscales actuales con un impuesto sobre la renta con menos exenciones, que tenga capacidad redistributiva real y que proteja los ingresos de los hogares más pobres.

${ }^{15}$ La mayoría de los sistemas fiscales de la región son demasiado complejos, debido a una multitud de exenciones y privilegios para ciertas actividades, sectores o grupos de contribuyentes. El resultado son impuestos a menudo distorsionan severamente la asignación de recursos y que generan bases tributarias estrechas y frágiles. Moverse hacia sistemas tributarios sencillos y con bases amplias y que creen un entorno favorable para la innovación y la creación de empresas es una de las apuestas más seguras para conseguir un crecimiento más rápido de la productividad y una mejora sostenible del bienestar y la equidad en la región.
} 
En tercer lugar, las administraciones tributarias deben fortalecerse para que todos los ciudadanos y las empresas cumplan con sus obligaciones tributarias. ${ }^{16}$

En cuarto lugar, son necesarios acuerdos y consensos institucionales para garantizar que los gobiernos locales tengan los recursos necesarios para actuar como agentes del desarrollo. ${ }^{17}$

En quinto lugar, las reformas tributarias para el desarrollo deberían crear sistemas fiscales que miren hacia el futuro. ${ }^{18}$

En relación a los tres primeros principios precitados, en mis obras de "Introducción al Estudio de Derecho Tributario", "Política Fiscal” y "Exegesis del Impuesto al Valor Agregado", he argumentado suficientemente además de proponer soluciones al respecto. Los dos últimos principios mencionados por el Presidente del BID enmarcan el tema abordado en éste texto y a ellos me referiré a continuación

\section{AUTONOMÍA FINANCIERA DE LOS MUNICIPIOS.}

El principal problema que afrontan los municipios es carecer de una suficiente capacidad económica para lograr satisfacer los servicios y otras prestaciones que se cumplan correctamente atendiendo a las necesidades a cargo de ellos.

\footnotetext{
${ }^{16}$ Reducir la elevada evasión fiscal y crear instituciones que garanticen que todos los agentes económicos y ciudadanos contribuyan con su parte al esfuerzo colectivo es un elemento esencial de la legitimación social y, como tal, un requisito para la sostenibilidad de cualquier sistema tributario diseñado para impulsar el desarrollo.

17 Para que la descentralización del gasto público sea sostenible, deben fortalecerse las fuentes de recursos propios de los gobiernos locales. Hay un gran potencial de recaudación local desperdiciado, especialmente en los impuestos a la propiedad.

${ }^{18} \mathrm{La}$ región de América Latina y el Caribe goza de una extraordinaria dotación en recursos naturales. No obstante, los impuestos ambientales o el actual diseño de los impuestos sobre las materias primas no reflejan esta situación. Para adaptar nuestro futuro a esta realidad, es necesario que nuestros sistemas fiscales creen incentivos para el uso más eficiente de los recursos naturales finitos de que disponemos, teniendo en cuenta las necesidades de las generaciones futuras. No podemos darnos el lujo de renunciar a la solidaridad intergeneracional.
} 


\section{La Hacienda Pública Municipal}

Volumen 12, Número 22 ene-jun 2020

Emilio Margáin Manaotou

El primer párrafo del artículo 115 de la Constitución Política de los Estados Unidos Mexicanos, expresa lo siguiente:

"Art. 115.- Los Estados adoptarán, para su régimen interior, la forma de gobierno republicano, representativo, popular, teniendo como base de su división territorial y de su organización política y administrativa el Municipio Libre, conforme a las bases siguientes:"

El Dr. Adalberto Saldaña Harlow, en su obra Constitución Política de los Estados Unidos Mexicanos, Comentada. Para conocer los derechos constitucionales del individuo y de la sociedad", en su comentario "Base de la división territorial", inciso a), nos dice: "Así como el artículo 43 establece que los Estados son las partes integrantes de la Federación", ahora en el texto del Artículo 115 se precisa que "la base de su división territorial (de los Estados) y de su organización política y administrativa", es el Municipio Libre (aunque ya no soberano como se dice de los Estados en el Artículo 40) y "Debe interpretarse que la base de la organización política y administrativa de la Federación y de su división territorial, son los Estados; de la misma manera, que la base de la organización política y administrativa de los Estados, y de su división territorial, son los Municipios". ${ }^{19}$

Pero los municipios, al igual que los Estados, requieren de los recursos económicos necesarios para poder sufragar los gastos indispensables para atender las necesidades sociales a su cargo; necesidades sociales que van en aumento cada año no así los recursos económicos para satisfacerlos, algunos teniendo un crecimiento económico natural y otros un sensible crecimiento económico, sea por su ubicación atraen inversiones públicas o privadas que los hace desarrollarse con mayor rapidez, no siempre acompañada, esa nueva riqueza con un aumento importante de sus recursos, sea por una mala administración, sea por inversiones suntuosas porque no producen el movimiento económico esperado o porque se presentan desviaciones ilegales de los mismos, en perjuicio de las necesidades sociales a atenderse año con año o porque surgen

${ }^{19}$ Edición 5 de febrero de 2005. 
nuevas inversiones que corresponde a los municipios atender, el caso es que la mayoría de ellos recurren con cierta frecuencia a créditos internos que en buen número de casos se desatienden y surge el endeudamiento que va lastrando económicamente a los municipios.

Conforme al artículo 73, fracción XXIX, de la Constitución Política de los Estados Unidos Mexicanos y 115 de esta Carta Magna, se precisan a cargo de los Municipios las funciones y servicios púbicos a su cargo, onerosos en sí y, por consiguiente, difíciles o casi imposible de atender totalmente, como son:

a) El servicio de agua potable, drenaje, alcantarillado, tratamiento y disposición de sus aguas residuales

b) Alumbrado público;

c) Limpia, recolección, traslado, tratamiento y disposición final de residuos;

d) Mercados y centrales de abastos;

e) Panteones;

f) Rastro;

g) Calles, parques y jardines y su equipamiento;

h) Seguridad pública, en los términos del artículo 21 de la Constitución federal, policía preventiva, municipal y tránsito, esto es, atender los reglamentos gubernativos y de policía, que el derecho administrativo denomina, reglamentos autónomos.

i) Los demás que las Legislaturas Locales determinen según las condiciones territoriales y socioeconómicas de los municipios, así como de su capacidad administrativa y financiera.

En tratándose de funciones o la prestación de servicios a su cargo, como el del agua, seguridad, etc., el tercer párrafo de la fracción III del artículo 115, 


\section{La Hacienda Pública Municipal}

Volumen 12, Número 22 ene-jun 2020

Emilio Margáin Manaotou

establece que "Sin perjuicio de su competencia constitucional, en el desempeño de sus funciones o la prestación de los servicios a su cargo, los municipios observarán lo dispuesto por las leyes federales y estatales".

$\mathrm{Y}$ en los municipios conurbados, el cuarto párrafo precisa que "Los municipios, previo acuerdo entre sus ayuntamientos podrán coordinarse y asociarse para la más eficaz prestación de los servicios públicos o el mejor ejercicio de sus funciones que les correspondan. En este caso y tratándose de la asociación de municipios de dos o más Estados, deberán contar con la aprobación de las legislaturas de los Estados respectivos. Asimismo cuando a juicio del Ayuntamiento respectivo sea necesario, podrán celebrar convenios con el Estado para que éste, de manera directa o a través del organismo correspondiente, se haga cargo en forma temporal de algunos de ellos, o bien se presten o ejerzan coordinadamente por el Estado y el propio Municipio", como es el caso de que al otorgarse a los municipios el cobro del impuesto predial, algunos Estados se negaron a entregar el padrón del predial para seguir controlando o participando en la recaudación de dicho impuesto, como el Estado

de México, y, otros, negándose a entregar parte del impuesto predial al proceder a formar dicho padrón.

En la fracción IV, se señala que "Los municipios administrarán libremente su hacienda, la cual se formará de los rendimientos de los bienes que les pertenezcan, así como de las contribuciones y otros ingresos que las legislaturas establezcan a su favor y en todo caso:

a) Percibirán las contribuciones, incluyendo tasas adicionales, que establezcan los Estados sobre la propiedad inmobiliaria, de su fraccionamiento, división, consolidación, traslación y mejora así como las que tengan por base el cambio de valor de los inmuebles. Celebrar convenios con el Estado para que éste se haga cargo de algunas de las funciones relacionadas con la administración de esas contribuciones; 
b) Las participaciones federales, que serán cubiertas por la Federación a los Municipios con arreglo a las bases, montos y plazos que anualmente se determinen por las Legislaturas de los Estados, y como son las que señala la fracción XXIX del artículo 73 de la Constitución.

El problema de los municipios es que carecen de legislatura propia y es la del Estado la que debe aprobar su Ley de Ingresos anualmente y la creación de nueva contribuciones o aumento de las que están en vigor.

Conforme a la fracción III, los municipios tendrán a su cargo las funciones y servicios públicos siguientes que puede gravar con impuestos y derechos:

a) Agua potable, drenaje, alcantarillado, tratamiento y disposición de sus aguas residuales;

b) Alumbrado público.

c) Limpia, recolección, traslado, tratamiento y disposición final de residuos;

d) Mercados y centrales de abasto.

e) Panteones.

f) Rastro.

g) Calles, parques y jardines y su equipamiento;

h) Seguridad pública, en los términos del artículo 21 de esta Constitución, policía preventiva municipal y tránsito; gravándose solamente la solicitud de estos servicios por prestadores de espectáculos púbicos, o son grandes comercios que arrojan extensa basura.

\section{Fuentes de ingresos de los municipios}

Iniciemos el examen de las fuentes de recursos económicos de carácter tributario que pueden tener apoyo en la Constitución Federal, como son:

a) Art. 73, fracción X, de la Carta Magna que nos dice:

"Artículo 73. El Congreso tiene facultad: 


\section{La Hacienda Pública Municipal}

Volumen 12, Número 22 ene-jun 2020

Emilio Margáin Manaotou

X. Para legislar en toda la República sobre hidrocarburos, minería, sustancias químicas, explosivos, pirotecnia, industria cinematográfica, comercio, juegos con apuestas y sorteos, intermediación y servicios financieros, energía eléctrica y nuclear y para expedir las leyes del trabajo reglamentarias del artículo 123".

Si la SCJN resolvió que los Estados pueden gravar con el impuesto sobre nómina a las actividades antes señaladas, visto que dicha contribución no influía en nada en sus actividades, por qué los municipios no pueden establecer contribución similar si ésta no afecta las actividades sobre hidrocarburos, minería, industria cinematográfica, comercio, juegos con apuestas y sorteos, intermediación y servicios financieros, energía eléctrica y nuclear.

Indudablemente que en forma directa dicho impuesto no influye en las actividades antes señaladas y así se declaró la constitucionalidad al aplicarse al comercio e industria de todo giro, juegos con apuestas y sorteos, etc., pero indirectamente sí, y ello se observó, al establecer los Estados ese impuesto y afectar a los servicios financieros creando los prestadores de estos servicios un beneficio por cheque que se expide por los depositantes de los bancos $u$ ahorradores.

Que este impuesto afecta la contratación de mano de obra, no se duda, pero ese efecto económico no evitó su creación. Que los municipios de crearlo afectarían aun más a la mano de obra, no se duda, pero que no hay impedimento legal alguno de tipo constitucional, ello indica que los promotores de tal contribución solo piensen en la obtención de mayores recursos económicos y se hará presión de carácter político por parte de organismos empresariales y por los Estados y Federación para que en las legislaturas locales no lo aprueben.

b) Art. 73, fracción XXIX; establece que el Congreso tiene facultades:

XXIX. Para establecer contribuciones:

10. Sobre el comercio exterior;

20. Sobre el aprovechamiento y explotación de los recursos naturales comprendidos en los párrafos $4^{\circ}$ y $5^{\circ}$ del artículo 27 ; 
3o. Sobre instituciones de crédito y sociedades de seguros;

40. Sobre servicios públicos concesionados 0 explotados directamente por la Federación; y

5o. Especiales sobre:

a) Energía eléctrica;

b) Producción y consumo de tabacos labrados;

c) Gasolina y otros productos derivados del petróleo;

d) Cerillos y fósforos;

e) Aguamiel y productos de su fermentación; y

f) Explotación forestal.

g) Producción y consumo de cerveza.

Por lo que toca a la energía eléctrica, la SCJN ha establecido jurisprudencia de que los Estados y Municipios no la pueden gravar, problema este que se ha presentado con motivo de que los municipios han creado un impuesto al consumo de energía eléctrica de la vía pública -luminarias- que deben pagar los propietarios de predios con frente a la vía pública.

Que los Estados y Municipios participan del rendimiento de estos impuestos especiales federales, pero existiendo el problema que señala el último párrafo de la fracción XXIX:

"Las entidades federativas participarán en el rendimiento de estas contribuciones especiales, en la proporción que la ley secundaria federal determine. Las legislaturas locales fijarán el porcentaje correspondiente a los Municipios, en sus ingresos por concepto del impuesto sobre energía eléctrica".

Esto es, de los impuestos especiales restantes: producción y consumo de tabacos labrados, cerillos y fósforos, aguamiel y productos de su fermentación, explotación forestal y producción y consumo de cerveza, ¿por qué los municipios no los pueden gravar o los Estados y se precisa en la ley el por ciento de participación de los municipios? 


\section{La Hacienda Pública Municipal}

Volumen 12, Número 22 ene-jun 2020

Emilio Margáin Manaotou

De los servicios públicos a cargo de los municipios que señala el artículo 115, en su fracción III, a excepción de alumbrado púbico, el resto es gravado por los municipios con derechos o tasas y contribuciones de mejoras.

De los impuestos locales que se han autorizados por el Congreso de la Unión, entre ellos los del artículo 43 de la Ley del Impuesto al Valor Agregado, se otorga participación a los municipios, pero no son suficientes para colmar, ya no la totalidad de los servicios, sino parte de ellos a satisfacción de sus habitantes.

Cuando en un municipio, por su localización, sea cercano a un puerto o zona centro del país con buenas comunicaciones o a la zona fronteriza, esencialmente del norte, se establecen empresas importantes que lo hacen crecer en servicios públicos municipales, pero que no pueden ser gravados más que con el impuesto predial municipal en el que participa el Estado, al poseer el padrón de los inmuebles en manos de particulares, no obtienen todo el beneficio esperado y sí realizan mayores erogaciones en vías púbicas, en abastecimiento de agua, energía eléctrica en las vías públicas, limpieza, en seguridad, etc., así como perciben mayores recursos económicos también las erogaciones, en lo antes expuesto les merma capacidad para atender debidamente los aumentos en sus gastos públicos y mayor administración a su cargo.

Lamentablemente, también crecen los problemas de seguridad pública al arribar problemas que no se padecían, como el comercio de drogas. Como ejemplo de lo expuesto tenemos los municipios de Zacatecas y Aguascalientes que con el establecimiento de una fábrica de cerveza y de fabricación de automóviles, los problemas no deseados aparecen al existir una mayor derrama económica producto de la creación de empleos con buena remuneración, un crecimiento comercial e industrial pequeño pero que da origen a demanda de mano de obra, etc., ello viene también a exigir una mayor demanda de recursos económicos para esos municipios.

Y si a lo anterior se agrega, desviación de los recursos por parte de las autoridades municipales o el aumento del costo de los servicios públicos real o simulado, tenemos que la mayoría de los municipios, y Estados también, al 
presentarse nuevas autoridades municipales éstas encuentran fuertemente comprometidos en lo económico y en participaciones en impuestos federales y estatales, percatándose que con lo que recaudan y reciben de la Federación y Estados no será suficiente para cubrir todos los gastos municipales, quedándoles como único recurso el solicitar préstamos bancarios con garantía de pago de las participaciones en impuestos federales o estatales, comprometiendo el futuro desempeño de las nuevas autoridades municipales que aparecerán a los dos o tres años, que ahora reclaman el auxilio de la Federación y para ello proponen una ley federal que venga a solucionarles sus adeudos y contar con mayores participaciones.

A lo anterior, los municipios se quejan del atraso con que la Secretaría de Hacienda y Crédito Público entrega las aportaciones que les corresponde mes tras mes, al retenérseles ilegalmente lo que a ellos les corresponde. ${ }^{1}$

Renán Herrera, Presidente de la Asociación Nacional de Alcaldes, que agrupa a ayuntamientos panistas, señaló que se trata de una problemática generalizada que afecta prácticamente a todos los municipios.

Que "en sus informes trimestrales sobre finanzas públicas, la SHCP reporta la falta de entrega de los recursos de distintos fondos aprobados para los municipios y estados.

Que "de enero a junio (del presente año de 2014) estaban programados 4 mil 971 millones de pesos para el Fondo Metropolitano, de los cuales solo se habían repartidos 302 millones.

Que "el fondo para fronteras tenía mil 500 millones y hasta junio no se había entregado ni un peso.

Que "una de las bolsas de recursos que año con año aumenta es la de Programa Regionales que, para el primer semestre tenía asignados 9 mil 16

\footnotetext{
1 Verónica Ayala, periódico REFORMA, Sección principal, lunes 1 de septiembre de 2014.
} 


\section{La Hacienda Pública Municipal}

Volumen 12, Número 22 ene-jun 2020

Emilio Margáin Manaotou

millones de pesos, de los cuales solo se había repartido 4 mil 141 millones, es decir, menos de la mitad de lo prometido..

Desconocemos las razones, Hacienda no da un argumento de peso o sólido. No tenemos una razón que nos permita saber por qué el atraso", manifestó Barbera, Presidente Municipal de Mérida.

"Perdemos el 50 por ciento de nuestra Administración esperando recursos y obras que son para los ciudadanos y que no se pueden realizar por éstas trabas" añadió.

Los apoyos provienen del fondo de distribución municipal del Presupuesto que los Ediles cuestionan con diputados.

"Bárbara Botello, presidente de la Federación Nacional de Municipios de México, que representa a ayuntamientos priistas, "reconoció que, según datos de la SHCP, en el primer semestre del año se había ejercido apenas el 30 por ciento de los recursos del Ramo 23.

“(El retraso) nos complica por la normativa para la aplicación de recursos porque luego nos piden regresar lo que no se ejerció a tiempo, pero que nos llega tarde", expuso Víctor Pérez, Alcalde de Santa Catarina, que ha recibido solo 40 de 80 millones de pesos para la infraestructura deportiva.

Que "de acuerdo con Hacienda en una muestra de 552 municipios 33.82\% le han transferido recursos asignados del Ramo 23 y $66.18 \%$ de los ayuntamientos están en espera de fondos". ${ }^{20}$

Para la perredista Leticia Quezada, presidenta de la Asociación de Autoridades Locales de México, "el problema del retraso en la llegada de recursos federales a los municipios no radica en la Secretaría de Hacienda, sino en los gobiernos de los estados".

La Jefa Delegacional en la Magdalena Contreras (del Distrito Federal), quien encabeza la administración del PRD, rechazó que exista incumplimiento en

20 Verónica Ayala, periódico REFORMA, página 9 de la sección citada. 
la entrega de los apoyos por parte de Hacienda y sostuvo que es en las Tesorerías estatales donde está el "atorón".

En respuesta a lo anterior, el Subsecretario de Egresos de la Secretaría de Hacienda y Crédito Público, expresó que ella entrega las participaciones correspondientes a los Estados y Municipios, por lo que considera que cree él que son los Estados los que no hacen oportuna entrega a los Municipios y que esas participaciones son por concepto de pavimentaciones, de infraestructura deportiva y de cultura, que se han repartido en su totalidad. ${ }^{21}$

Que "la Secretaría de Hacienda entrega con oportunidad los recursos que están etiquetados directamente a los municipios.

Esto es, que no ha habido demora de los recursos para las erogaciones mencionadas.

Sin embargo, el Presidente del Partido Acción Nacional, se comprometió a exigir a la Secretaría de Hacienda y Crédito Público que entregue a tiempo las aportaciones de los fondos federales a las presidencias municipales. ${ }^{22}$

"Nos hacemos cargo, como presidente del Comité Ejecutivo Nacional de la necesidad de insistir y exigir suficiencia de los recursos y oportunidad de su aplicación y en sus transferencias, porque estamos ya en el mes de septiembre y gran parte de los recursos aprobados para este año no han llegado".

El Alcalde de Mérida, Renán Herrera, se quejó de que Hacienda retiene los recursos en demérito de los municipios, y señaló como una gran falla de la dependencia que, cuando al fin llegan, tiene que ser ejercidos en menos de 90 días, esto es, el famoso Presupuesto por Programa que si no se gasta la cantidad asignada para determinado programa, se reduce para el siguiente ejercicio la cantidad que se había signado para el ejercicio anterior.

\section{El moche}

21 Verónica Ávila, periódico REFORMA, 2 de agosto de 2014.

22 REFORMA, sábado 6 de septiembre de2014. 


\section{La Hacienda Pública Municipal}

Volumen 12, Número 22 ene-jun 2020

Emilio Margáin Manaotou

Otra calamidad para el desarrollo económico de los municipios es lo que se tuvo conocimiento a principios de año, de 2014, y quien sabe desde cuando vienen padeciendo dichos entes, es el famoso "moche" que sufren ellos y que consiste en lo siguiente:

Al aprobarse el Presupuesto de Egresos para el siguiente ejercicio fiscal en el último trimestre del año que concluye, que se aprueba exclusivamente por la Cámara de Diputados en los términos del artículo 74 de la Constitución Política de los Estados Unidos Mexicanos, se asigna a ciertos Diputados varios millones de pesos para ser entregados a los municipios de la zona en que fueron electos y ello se realiza previa aceptación de las autoridades municipales de repartirse o aceptar ellos, el que parte de la asignación se "reparta" entre los Diputados y el Municipio, de ahí que hoy se hable de "moche", esto es, si al Presidente Municipal se le propone asignarle una inversión de cinco millones de pesos deberá aceptar que el Diputado únicamente asignará tres o tres millones y medio de pesos debiendo entregarse dos o uno y medio en efectivo para el señor Diputado, lo cual merma la inversión a efectuarse en nuevos servicios municipales o en el mantenimiento de los existentes.

Ha habido Presidentes Municipales que al terminar su periodo de gobierno, tres años, se quejan amargamente del "moche" pues si no lo aceptan no se les asignará los cinco millones y no contaran con el remanente del "moche". Es triste y vergonzoso para esos Diputados Federales que en su periodo, también de tres años, se retiran millonarios. Esto afecta a los municipios que por inversiones privadas están en pleno desarrollo y requieren de recursos 
económicos para contribuir a un óptimo desarrollo y a los importantes que por su crecimiento de población están necesitados de desarrollar obras públicas o adquirir ciertos bienes para la prestación de servicios públicos.

\section{Las adquisiciones municipales}

Este es otro problema que padecen el grueso de los municipios: el de adquisición de bienes y de servicios al sector privado: incremento de los precios sobre el costo normal de ellos.

Se supone que un municipio mediano o de cierta importancia debería obtener mejores precios en la adquisición de bienes y servicios frente a los que pagan los particulares o consumidores finales, pero ello no es así, pues el precio aumenta a medida que crece el valor de la operación, esto es, el precio de adquisición aumenta y no en beneficio del fabricante o comerciante sino en beneficio de la autoridad municipal, que confiamos que esto desaparezca en los chicos y medianos pero que no siempre es así, o bien cuando se efectúan adquisiciones suntuarias, como la compra de vehículos nuevos para los nuevos funcionarios.

Los municipios padecen buen número de calamidades "humanas" de sus administradores orillados a ellas o provocados por ellos mismos.

De ahí que bien puede precisarse que en el manejo del gobierno de un municipio el problema "humano" que padecen, hace naufragar el que surjan autoridades municipales que desean actuar con honradez y limpieza.

Lamentablemente Presidentes municipales de cualquier partido político han incurrido, salvo verdaderas excepciones, en el mal manejo de los recursos económicos que por distintos conceptos han percibido, sean por contribuciones, participaciones federales o estatales, endeudamientos con la banca, originando 


\section{La Hacienda Pública Municipal}

Volumen 12, Número 22 ene-jun 2020

Emilio Margáin Manaotou

un endeudamiento municipal imposible de cubrir en los tres años siguientes o en seis o nueve años y si los nuevos Presidentes se dedican a cubrir el endeudamiento solo van a concretarse a cubrir los servicios ordinarios y no habrá nueva inversión, pasando su período de tres años sin satisfacer nuevas necesidades municipales, salvo que acuda en su auxilio el Gobierno Federal ya que los señores Gobernadores estatales están heredando una situación económica similar.

\section{Situación Actual del Erario Municipal}

Salvo verdaderas excepciones, los Municipios viven en franca bancarrota económica. Sus necesidades crecen en proporción geométrica, mientras que sus ingresos lo hacen en proporción aritmética.

Hoy en día las entidades públicas, llámense Federación, Distrito Federal, Estados o Municipios, tienen mayores responsabilidades y necesidades que satisfacer. No se desconoce que la Federación tiene a su cargo la satisfacción de necesidades nacionales; que no busca beneficiar a determinada zona del país sólo por razones políticas o de preferencia; que el gasto que realiza tiende a colmar metas imprescindibles de alcanzarse; pero con base en todo esto pretender restar importancia a los Municipios, como entidades públicas que también tienen a su cargo la satisfacción de necesidades sociales similares, es ignorar la realidad.

Cierto es que los Municipios no atienden problemas como el del abaratamiento del costo de la vida; precios bajos en artículos de primera necesidad, construcción de viviendas, educación técnica o superior gratuitas, etc.; pero la existencia de estas necesidades entre sus habitantes, en forma grave y sin satisfacción, les ocasionan serios problemas, que van desde la delincuencia infantil y juvenil, hasta la creación sin ningún control, de nuevos centros de población que carecen de toda clase de servicios públicos, todo lo 
cual viene a comprender seriamente las haciendas municipales, de por sí ya pobres.

La falta de recursos, sobre todo en los pequeños Municipios, origina tolerancia de actividades consideradas inmorales, aun cuando no ilegales, así como la aplicación rigorista en extremo de los reglamentos de policía y buen gobierno, con el objetivo lograr ingresos para las arcas municipales. Así vemos cómo la mayoría de los Municipios sin recursos económicos, y también un buen número de los llamados importantes, perciben, si no como principales, elevados recursos de la explotación del vicio (cantinas, bares, casas de asignación, etc.); multas por a detención, con cualquier pretexto, de personas en estado de embriaguez, infracciones de tránsito originadas por cambios en la circulación y que los automovilistas desconocen, sobre todo, por falta de avisos oportunos o señales durante la noche, etcétera.

Agudiza la situación económica de los Municipios la mala administración de los recursos o la sustracción de los mismos en beneficio de sus funcionarios, pues los habitantes se niegan a colaborar con aportaciones mayores a las que las leyes les obligan peleándoles, inclusive, toda gestión tendiente al aumento de los gravámenes o precios existentes.

En esos casos, para que los contribuyentes entreguen más de lo que legalmente les corresponde, los funcionarios municipales deben ser sus amigos 0 restituirles con favores o privilegios sus desprendimientos, o bien, que simplemente les demuestren su agradecimiento. De no ser así, no hay colaboraciones extraordinarias.

Hoy en día, los Municipios requieren del auxilio económico extraordinario de sus habitantes y para logarlo sus funcionarios deben no sólo actuar con la mayor limpieza posible en el manejo de los fondos públicos, sino aceptar su participación en la cosa pública mediante el respeto al derecho de voto, y también solicitando su parecer u opinión en las decisiones más importantes, a través d comisiones o consejos de planeación. Únicamente así con el respaldo económico, 


\section{La Hacienda Pública Municipal}

Volumen 12, Número 22 ene-jun 2020

Emilio Margáin Manaotou

moral y cívico de sus habitantes, pueden los Municipios sortear los grandes problemas y satisfacer las crecientes necesidades sociales a su cargo.

\section{Reforma al Artículo 115 Constitucional}

Deseando otorgarse una verdadera independencia económica a los Municipios se procedió a reformar el artículo 115 de la Constitución Federal, estableciéndose en la fracción IV que "Ios Municipios administrarán libremente su hacienda, la cual se formará con los rendimientos de los bienes que les pertenezcan, así como de las contribuciones y otros ingresos que las legislaturas establezcan a su favor..."23

Se les otorga el derecho de percibir:

a) Las contribuciones, incluyendo tasas adicionales, que establezcan los Estados sobre la propiedad inmobiliaria, de su fraccionamiento, división, consolidación, traslación y mejora, así como las que tengan por base el cambio de valor de los inmuebles;

b) Las participaciones federales, que serán cubiertas por la Federación con arreglo a las bases, montos y plazos que anualmente se determinen por las legislaturas de los Estados, y

c) Los ingresos derivados de la prestación de servicios públicos a su cargo.

Lo anterior ha favorecido a los Municipios importantes, no así a los pequeños, quienes han visto la resistencia de la administración paraestatal federal para pagar el impuesto predial, debido a que el penúltimo párrafo de la fracción IV establece que: "Sólo estarán exentos los bienes del dominio público de la Federación, de los Estados o de los Municipios, salvo que tales bienes sean utilizados por entidades paraestatales o por particulares, bajo título para fines administrativos o propósitos distintos a los de su objeto público". Por ello, el artículo 17 de la Ley de Ingresos de la Federación para el Ejercicio Fiscal de 1997,

${ }^{23}$ Publicada en el Diario Oficial de la Federación del 3 de febrero de 1983. 
nos dice: "Quedan sin efecto las exenciones relativas a los gravámenes a bienes inmuebles previstas en leyes federales a favor de organismos descentralizados sobre contribuciones locales, salvo en lo que se refiere a bienes de propiedad de dichos organismos que se consideren del dominio público de la Federación".

Acudiendo a la Ley Federal de Bienes Nacionales y a los ordenamientos similares de los Estados se precisa cuándo se está frente a un bien del dominio público coincidiendo en que los bienes destinados a un servicio público de una Secretaría de Estado o Departamento Administrativo u organismo descentralizado, son bienes del dominio público.

El problema reside en que buen número de organismos descentralizados tienen en propiedad inmuebles que no destinan ni van a estar destinados a un servicio público, pues se han adquirido para construir unidades habitacionales para sus trabajadores o para subdividirlos en lotes habitacionales que enajenan a su personal y se niegan a pagar el impuesto predial en tanto no los enajenan. Pero estos terrenos no pueden considerarse del dominio público.

\section{CONCLUSIONES}

El principal problema que afrontan los municipios es carecer de una suficiente capacidad económica para lograr satisfacer los servicios y otras prestaciones de las necesidades sociales a su cargo. Además de carecer de legislatura propia (y es la del Estado la que debe aprobar su Ley de Ingresos anualmente y la creación de nueva contribuciones o aumento de las que están en vigor).

Los municipios, al igual que los Estados, requieren de los recursos económicos necesarios para poder sufragar los gastos indispensables para 


\section{La Hacienda Pública Municipal}

Volumen 12, Número 22 ene-jun 2020

Emilio Margáin Manaotou

atender las necesidades sociales a su cargo; necesidades sociales que van en aumento cada año no así los recursos económicos para satisfacerlos.

No hay impedimento legal alguno de tipo constitucional para que los municipios puedan establecer contribución similar a la establecida por los estados sobre hidrocarburos, minería, industria cinematográfica, comercio, juegos con apuestas y sorteos, intermediación y servicios financieros, energía eléctrica y nuclear.

El objetivo contemplado en la exposición de motivos de la Ley de Coordinación Fiscal de fortalecer a los estados y hacerlos menos dependientes de la Federación no se ha alcanzado y el resultado es exactamente lo contrario.

Las reformas realizadas a lo largo de 34 años de la vigente Ley de Coordinación Fiscal se han dado en dirección del aumento cada año del porcentaje de participaciones hacia los Estados y Municipios, pero se ha dejado de lado el establecer mecanismos para que se entreguen a tiempo y en cantidades suficientes las participaciones y transferencias para satisfacer las necesidades sociales a cargo de dichos entes.

La mayoría de los municipios, recurren con cierta frecuencia a créditos internos que en buen número de casos se desatienden y surge el endeudamiento que va lastrando económicamente a los municipios.

Otra calamidad para el desarrollo económico de los municipios es el famoso "moche" al aceptar "compartir, los recursos asignados, a los diputados para ser entregados a los municipios de la zona en que fueron electos" lo que merma la inversión a efectuarse en nuevos servicios municipales o en el mantenimiento de los existentes.

Otro problema: incremento de los precios sobre el costo normal de ellos, en la adquisición de bienes y de servicios al sector privado.

Los municipios padecen buen número de calamidades "humanas" de sus administradores orillados a ellas o provocados por ellos mismos. 
En tanto no se resuelvan estos problemas que aquejan al grueso de los municipios, sin distinguir entre chicos, medianos e importantes, hablar sobre autonomía financiera de ellos es estar divorciados de la realidad en que viven. 


\section{La Hacienda Pública Municipal}

Volumen 12, Número 22 ene-jun 2020 Emilio Margáin Manaotou

\section{REFERENCIAS BIBLIOGRÁFICAS Y WEBGRAFÍA}

Diario Reforma, Sección principal, 2 de Agosto de 2014

Diario Reforma, Sección principal lunes 1 de Septiembre 2014

Diario Reforma, Sección principal sábado 6 de Septiembre 2014

MARGÁIN MANAUTOU Emilio,Nociones de Política Fiscal,México, Ed.Porrúa, 1998.

"Introducción al Estudio de Derecho Tributario", México, Ed. Porrúa, 2010. "Exegesis del Impuesto al Valor Agregado", México, Ed. Porrúa, 1998.

MORENO, Luis Alberto, "Recaudar no basta: Los Impuestos como Instrumento de Desarrollo", Ed., BID, 2012.

SALDAÑA HARLOW, Adalberto, "Constitución Política de los Estados Unidos Mexicanos, Comentada”,México,2005.

\section{Legislación}

Constitución Política de los Estados Unidos Mexicanos

Exposición de Motivos de la Propuesta de la nueva la Ley de Coordinación Fiscal para 1977

Exposición de Motivos de la Propuesta de reforma a la Ley de Coordinación Fiscal para 2013

Ley de Coordinación Fiscal

Diccionario Eco-Finanzas,2015[online]Disponible en :

http://www.eco-finanzas.com/diccionario/P/P.htm^ [consultado el12/VI/2015]

KPMG Firma Mexicana miembro de la red de firmas miembro de KPMG afiliadas a KPMG International Cooperative , 2014(online) Disponible en : http://www.kpmg.com/MX/es/IssuesAndlnsights/ArticlesPublications/Documents/ Estudios/2013/Reforma-Fisca-2014-Final.pdf [consultado el12/VI/2015] 